\title{
Retinas of the Diurnal Rodent Arvicantbis ansorgei Are Highly Resistant to Experimentally Induced Stress and Degeneration
}

\author{
Domitille L. Boudard, ${ }^{1}$ Niyazi Acar, ${ }^{2}$ Lionel Bretillon, ${ }^{2}$ and David Hicks ${ }^{1}$
}

\begin{abstract}
Purpose. Environmentally induced stress plays a significant role in retinal degeneration and blindness both in animals and in humans. Among such sources of stress, phototoxicity is well studied and has been shown to lead to photoreceptor-specific loss in a number of species. However, the vast majority of studies have been conducted in nocturnal, albino rod-dominant rat and mouse strains, and the pertinence of such findings to human pathology and cone loss is debatable. The authors examined retinal vulnerability to damage in the diurnal murid rodent Arvicanthis ansorgei, a pigmented species with a large number of cones.
\end{abstract}

Methods. The authors used established protocols for exposing animals to a wide range of lighting conditions (variable intensity, duration, spectrum, previous light history, and time of exposure) and injecting $N$-methyl- $N$-nitrosourea (MNU); each procedure is reported to produce rapid and complete photoreceptor-specific damage. Animals then underwent electroretinography to record rod and cone function and were subsequently euthanized and used for immunohistochemical analysis of retinal structure and quantification of free fatty acids.

Results. These standard regimens produced no detectable detrimental effects on $A$. ansorgei retinal phenotype, function, or structure. Partial retinal damage in $A$. ansorge $i$ was induced by very intense blue light or elevated doses of MNU. This resistance was not attributable to differences in lipid composition (specifically, docosahexaenoic acid) between $A$. ansorgei and susceptible strains of mice and rats.

Conclusions. The retina of this species exhibits exceptionally high resistance to damage from light and toxins such as MNU. (Invest Ophthalmol Vis Sci. 2011;52:8686-8700) DOI:10.1167/ iovs.11-8162

$\mathrm{V}$ isual handicap is a major societal health problem, representing a huge burden on health care-related expenses and inflicting chronic suffering on the affected population. In industrialized nations, the main causes of blindness affecting the retina are glaucoma, diabetes, and age-related macular degeneration (AMD). ${ }^{1}$ These diseases are all complex multifactorial entities, and

From the ${ }^{1}$ Département de Neurobiologie des Rythmes, Université de Strasbourg, Institut des Neurosciences Cellulaires et Intégratives, Strasbourg, France; and the ${ }^{2}$ Eye and Nutrition Research Group, Université de Bourgogne, Dijon, France.

Supported by Région Alsace, Alcon Pharmaceuticals Ltd. (DLB), and Fondation Fritz Tobler (DH).

Submitted for publication July 4, 2011; revised August 31, 2011; accepted September 19, 2011.

Disclosure: D.L. Boudard, None; N. Acar, None; L. Bretillon, None; D. Hicks, None

Corresponding author: David Hicks, Département de Neurobiologie des Rythmes, CNRS UPR 3212 Université de Strasbourg, Institut des Neurosciences Cellulaires et Intégratives, 5 rue Blaise Pascal, 67084 Strasbourg Cedex, France; photoreceptor67@hotmail.com. the underlying pathogenic mechanisms are only partially understood. Furthermore, there are few options for treating these debilitating conditions. ${ }^{2,3}$ Although there is a clear genetic component in these diseases (e.g., some forms of glaucoma are linked to mutations in the optineurin gene, ${ }^{4}$ diabetic retinopathy is linked to polymorphisms in the melatonin receptor, ${ }^{5}$ and AMD is linked to polymorphisms in the alternative complement pathway ${ }^{6}$ ), they are all thought to be strongly influenced by environmental risk factors. These risk factors involve, among others, cigarette smoking, obesity, heart disease, infection, and light exposure. ${ }^{7-9}$ There is some evidence that short wavelength light may aggravate $\mathrm{AMD},{ }^{8}$ although the involvement is controversial. In hereditary blinding diseases in which the causal mutations are involved in the visual cycle, it is clear that light exposure accelerates degeneration. ${ }^{10}$

Since the discovery of the phenomenon of "photochemical" light toxicity by Noell in 1966, the underlying mechanisms have been extensively explored by several groups (see Refs. 11-13 for reviews). Class I photochemical damage is closely related to the rhodopsin visual cycle: not only does the action spectrum of light damage coincide with the absorption spectrum of rhodopsin, ${ }^{14}$ the degree of retinal damage is also positively correlated with the rhodopsin content in the retina before exposure to light. ${ }^{15}$ Furthermore, photochemical damage is reduced when the visual cycle is inhibited by halothane $^{16}$ or 13 -cis-retinoic acid ${ }^{17}$ or when the rate of rhodopsin regeneration is reduced by a nearly complete depletion of docosahexaenoic acid (DHA) or by the lack of RPE-65, which is involved in the regeneration of 11-cis-retinal. Arrestin ${ }^{18}$ or rhodopsin kinase ${ }^{19}$ knockout mice have an increased susceptibility to light damage, again suggesting that light damage is mediated by rhodopsin because these transgenic strains exhibit prolonged activation of metarhodopsin II.

Photoreceptor-specific degeneration has also been reported after injection of the alkylating agent $N$-methyl- $N$-nitrosourea (MNU). This carcinogen is thought to provoke lesions by methylation at the O-6 position of guanine or phosphate groups in DNA. A single parenteral injection leads to widespread onset of apoptosis within the outer nuclear layer (ONL) after 24 hours in mice, hamsters, and rats. ${ }^{20-22}$ Almost complete destruction of the ONL is seen by 1 week after injection, whereas the other layers of the retina are relatively spared. ${ }^{21}$ The degeneration can be blocked by interference with apoptosis, such as by using the X-linked inhibitor of apoptosis ${ }^{23}$ or by caspase inhibition, ${ }^{24}$ but also by neuroprotective pretreatment with DHA. $^{25}$

Although light damage and MNU injection both lead to photoreceptor death, the large majority of data has been obtained using nocturnal rodents, principally albino strains. It is still difficult to extrapolate the findings to humans, or in general to species that are active during the day and that depend largely on conemediated photopic vision. The reaction of cones to phototoxicity is not well understood because cones have been reported to be both more sensitive ${ }^{26}$ or less sensitive ${ }^{27}$ than rods. We thus 
undertook an extensive series of experiments to examine the extent and pattern of induced retinal damage in Arvicanthis ansorgei. The retina of this pigmented diurnal murid rodent (member of the Muridae family, which includes mice, rats, and gerbils) exhibits a high percentage of cones compared with conventional nocturnal rodents (33\% cones in $A$. ansorgei, ${ }^{28} \sim 2 \%$ in Rattus norvegicus, ${ }^{29} \sim 3 \%$ in Mus $_{\text {musculus }}{ }^{30}$ ). In addition, the cones display a strict orderly arrangement as the two scleral-most cell body layers within the ONL and can be identified by their nuclear morphology and by a range of immunologic markers. ${ }^{28,31}$ To our surprise the species showed almost complete resistance to light damage, irrespective of the conditions used. Furthermore, this species was also highly insensitive to MNU-induced retinal degeneration. Hence, diurnal animals might have developed mechanisms rendering them relatively insensitive to retinal damage.

\section{Methods}

\section{Animals}

Animal treatment and experimentation adhered to rules established within our institution (animal experimentation authorization 67-132) and also adhered to guidelines issued by the ARVO Statement for the Use of Animals in Ophthalmic and Vision Research. We used a strict number of animals necessary to perform valid statistical data treatment, and the animals were inspected at regular intervals during the experimental period for their general health. Young adult (2-6 months) male $(\sim 150 \mathrm{~g})$ A. ansorgei were obtained from a breeding colony in our animal facilities (Chronobioton/IFR 37, Strasbourg, France). These animals exhibit a fully diurnal activity pattern, as monitored by wheel running and general locomotion. ${ }^{32}$ By definition, the active phase in this diurnal species is from zeitgeber (ZT) 0 (time of lights on [7 AM]) to ZT12 (time of lights off [7 PM]), and the resting phase is from ZT12 to ZT0. In addition, inbred laboratory strains of mice and rats were used as positive controls. Albino Balb/c mice were purchased from Charles River (L'Arbresle, France) and Harlan Laboratories (Gannat, France), albino Wistar rats were obtained from our own breeding facilities, pigmented 129S6/SvEvTac mice were obtained from Taconic (Lille Skensved, Denmark), pigmented Long-Evans rats were obtained from Janvier Laboratories (le Genest-Saint-Isle, France), and pigmented Brown Norway rats and pigmented $\mathrm{C} 57 \mathrm{BL} / 6$ mice were raised at the animal facility in INRA (Dijon, France). In phase opposition to $A$. ansorge $i$, these nocturnal species and strains exhibit an active phase from ZT12 to ZT0 (i.e., 7 PM-7 AM), and a resting phase from ZT0 to ZT12. All animals were kept in air-conditioned rooms at $22^{\circ} \mathrm{C} \pm 2{ }^{\circ} \mathrm{C}$, and, unless stated otherwise, they were maintained under a standard 12-hour-12-hour light/dark (LD) cycle with average ambient light levels during the day of $\sim 100$ lux (measured at the level of the central racks). Animals were supplied ad libitum with water and standard rat chow. Food intake and body weight were recorded on a daily basis during the entire experiment. Animals were killed by an approved painless protocol (decapitation) after $\mathrm{CO}_{2}$ anesthesia at different time points after intense light exposure (ILE) or MNU intraperitoneal injection.

\section{Intense Light Exposure}

We examined the structural and phenotypic characteristics of -ILE (unexposed) and +ILE (light-exposed) groups under a wide variety of conditions.

Our initial experiments used published values of light intensity and exposure duration known to induce damage in rats and mice. $A$. ansorgei were exposed to either 5 or 12 klux for 30 minutes, 1 hour, or 2 hours and were euthanized 1 week after exposure.

In the following experiments, we tested additional parameters known to affect the degree of phototoxic damage, namely circadian time of exposure, ${ }^{33,34}$ light-rearing history, ${ }^{33-35}$ and light wavelength. ${ }^{12}$

The second series examined the effects of higher ILE (20 klux) in A. ansorgei. Our frame device could not generate such values, and we used directed illumination from optical fiber lamps. Fiber guides were adjusted in a manner such that anesthetized animals received 20 klux at the level of the left cornea. Animals were reared for 2 weeks in dim LD (20 lux) and then anesthetized and exposed for 2 hours during their active phase (ZT5-6 [12 AM-1 PM]) at 20 klux.

The third series explored the effect of time of exposure. It has been shown for albino rats that light damage is under circadian control because ILE performed during the night leads to greater damage than in the daytime. ${ }^{36}$ This differential effect is maintained under DD conditions (animals exposed during subjective day or subjective night) and can be phase-shifted. ${ }^{37}$ A. ansorge $i$ were hence exposed for 4 hours at 11 klux; one group was exposed during its active phase (ZT5-9 [12 AM-4 PM]), and one group was exposed during its resting period (ZT17-21 [12 PM- 4 $\mathrm{AM}])$. Animals were killed 50 hours after exposure.

The fourth series was used to investigate light-rearing history. In our animal facility, light intensity at cage level varied between 50 and 300 lux, depending on shelf height and proximity to the lamp, which is potentially sufficient to induce partial protection against ILE. ${ }^{38}$ Therefore, in this experiment, A. ansorge $i$ were reared in dim light LD cycles (20-50 lux) for 4 weeks before 8-hour exposure at 6 klux. As for the previous experiments, animals remained in the dark for 12 hours immediately before exposure.

A final series exploring the effects of short-wavelength light was performed. Spectral quality of light radiation is an important parameter of retinal damage. ${ }^{12}$ Under the experimental conditions used here, blue light exposure times of 1 minute were sufficient to induce extensive photoreceptor loss in either pigmented or albino mice (C. Remé, personal communication, 2009). To our knowledge, the effects of blue light on photoreceptors of a diurnal rodent have not been examined. Because of the observed resistance to ILE in A. ansorgei, we exposed them for 5, 15, and 45 minutes. They were maintained in dim light LD for 2 weeks before blue ILE, which was performed at ZT6-11 (1 PM-6 PM, during the active phase).

The entire experimental series is given in Supplementary Table S1 (http://www.iovs.org/lookup/suppl/doi:10.1167/iovs.11-8162/-/DC Supplemental), where conditions for each experiment are detailed. For purposes of clarity, only the general steps of the ILE protocol will be described hereafter.

Animals were dark adapted for at least 12 hours before exposure. In some trials, animals were maintained in either permanent darkness (DD) or constant illumination (LL), and others were maintained under dim LD cycles. Animals were kept in clear plastic cages wrapped on the outside with aluminum foil to reflect and increase light intensity within the cages. For all ILE experiments with pigmented animals, pupils were previously dilated by serial topical application onto the cornea in dim red light. To obtain full mydriasis and cycloplegia, 1 drop of cyclopentolate $0.5 \%$ (Skiacol; Alcon Laboratories, Houston, TX) was first applied to the cornea 30 minutes before exposure. Fifteen minutes later (or 15 minutes before exposure), 1 drop of phenylephrine 5\% (Neosynephrine Faure, Europhta, Monaco) or tropicamide $(2 \mathrm{mg} / 0.4 \mathrm{~mL})$ (Tropicamide; Faure, Novartis Pharma, Bern, Switzerland) was put on the cornea. Dilation was effective for approximately 8 hours. For ILE experiments involving fiberoptic illumination, animals were anesthetized. A. ansorge $i$ were anesthetized with a mixed solution of ketamine (Ketamine; Virbac, Carros, France) $150 \mathrm{mg} / \mathrm{kg}$ and xylazine (Rompun $2 \%$; Bayer Pharma, Puteaux, France) $10 \mathrm{mg} / \mathrm{kg}$ injected at $0.5 \mathrm{~mL} / 100 \mathrm{~g}$ body weight (body weight). Rats were anesthetized with a mixture of tiletamin/zolazepam (Zoletil 20; Virbac), $0.4 \mathrm{mg} / \mathrm{kg}$ and xylazine (Rompun $2 \%$ ) $0.67 \mathrm{mg} / \mathrm{kg}$ injected at $0.25 \mathrm{~mL} / 100 \mathrm{~g}$ body weight. Injections were given intraperitoneally in the lower left quadrant of the abdomen to avoid vital organs. After ILE, animals were returned to darkness for one night. - ILE animals were maintained under the same conditions as each experimental group and underwent the same anesthetic procedure but did not receive pupil dilation treatment and were not exposed to bright light. The illumination apparatus consisted of a custom-made aluminum frame with an overhead lamp housing two cool white fluorescent lamps (TL-D 36W/965; Philips, Somerset, NJ). The frame could be adjusted in height to vary light intensity without varying the spectral composition of the light. Light intensity was measured by a handheld lux meter at the base of the cage. For intensities 
$>15$ klux, we used a fiberoptic infrared-free cold light source (CL 1500 ECO; Carl Zeiss MicroImaging GmbH, Göttingen, Germany).

The blue ILE system consisted of a xenon short-arc reflector lamp (230 V, $50 \mathrm{~Hz}, 120 \mathrm{~W}$; Intralux MDR 100; Volpi, Schlieren, Switzerland) with interference filters to eliminate ultraviolet and infrared radiation and a liquid fiberoptic light guide $(8 \mathrm{~mm}$ in diameter) to the animal's cornea. ${ }^{39}$ The optical system included a $403 \pm 10$-nm bandwidth interference filter. A heat sink was also provided to keep body temperature constant during the time of ILE.

\section{$\boldsymbol{N}$-Methyl- $\boldsymbol{N}$-Nitrosourea Injection}

To test the sensitivity of $A$. ansorgei retina to other types of stress, we used another approach to induce the degeneration of cones and rods through injection of a known PR toxin. MNU was purchased from Sigma-Aldrich Chimie S.a.r.l. (Saint-Quentin Fallavier, France) and kept at $4^{\circ} \mathrm{C}$ in the dark. MNU solution was freshly prepared in $\mathrm{NaCl} 0.9 \%$ immediately before injection. Vehicle was prepared using $0.9 \% \mathrm{NaCl}$ and $0.05 \%$ acetic acid (the commercial stock solution contains $2.3 \%$ acetic acid). Solutions of MNU were prepared at $10 \mathrm{mg} / \mathrm{mL}$ concentration (solubility, $1.4 \%$ ) and were given by intraperitoneal injection. $A$. ansorge $i$ were injected at 75,100 , or $150 \mathrm{mg} / \mathrm{kg}$ body weight, and rats were injected at $75 \mathrm{mg} / \mathrm{kg}$ body weight. ${ }^{40}$ All injections were performed at the same time of day (ZT4-6 [11 AM-1 PM]).

\section{Electroretinography}

Animals were dark adapted overnight, and their pupils were dilated with tropicamide (Mydriaticum Stulln; Pharma Stulln, Nabburg, Germany) and phenylephrine 5\% (Neosynephrin-POS 5\%; Ursapharm, Saarbruecken, Germany) eye drops. Animals were anesthetized by intraperitoneal injection of a combination of ketamine (Imalgene; Merial, Lyon, France) $150 \mathrm{mg} / \mathrm{kg}$ body weight and xylazine (Rompun $2 \%$; Bayer Pharma) $10 \mathrm{mg} / \mathrm{kg}$ body weight Animals were positioned on a temperature-controlled $\left(38^{\circ} \mathrm{C}\right)$ cushion on a sliding platform. Silver needle electrodes served as reference (forehead) and ground (tail) electrodes, and gold-wire ring electrodes served as active electrodes. Methylcellulose (Humigel; Virbac) was applied to ensure good electrical contact and to keep the cornea hydrated during the entire procedure. Electroretinograms (ERGs) were performed according to previously described procedures. ${ }^{41-43}$ The ERG equipment consisted of a Ganzfeld bowl, a direct current amplifier, and a PC-based control and recording unit (Physiotrace; Estaris Monitoring, Lille, France). ERGs were recorded from both eyes simultaneously after the animals were placed in the Ganzfeld bowl. Bandpass filter width was 1 to $300 \mathrm{~Hz}$ for single-flash and flicker-stimuli recordings. Bandpass filter cutoff frequencies were 0.1 and $3000 \mathrm{~Hz}$. Single-flash and flicker recordings were obtained under both dark-adapted (scotopic) and light-adapted (photopic) conditions. Light-adaptation was performed with a background illumination of $30 \mathrm{~cd} \cdot \mathrm{s} / \mathrm{m}^{2}$ presented 10 minutes before recording to stabilize photopic responses. Illumination strength was varied using different actinic filters placed below the lamp housing. Single white-flash stimulus intensity ranged from -4 to $1.5 \log \mathrm{cd}$. $\mathrm{s} / \mathrm{m}^{2}$ under scotopic conditions and from -2 to $1.5 \log \mathrm{cd} \cdot \mathrm{s} / \mathrm{m}^{2}$ under photopic conditions, divided into 10 and 8 steps, respectively. Ten responses were averaged with an interstimulus interval of either 5 seconds (for $-4,-3,-2,-1.5,-1$, and $-0.5 \log \mathrm{cd} \cdot \mathrm{s} / \mathrm{m}^{2}$ ) or 17 seconds (for $0,0.5,1$, and $1.5 \log \mathrm{cd} \cdot \mathrm{s} / \mathrm{m}^{2}$ ). In separate experiments, we obtained responses to flicker stimuli for a fixed frequency $(6 \mathrm{~Hz})$ with a range of intensities (from -5.0 to $1.45 \mathrm{log} \mathrm{cd} \cdot \mathrm{s} / \mathrm{m}^{2}$ in steps of 0.35 logarithmic units)

\section{Histology and Immunohistochemistry}

Eyes were quickly removed for immersion fixation in buffered $2 \%$ or $4 \%$ paraformaldehyde in $0.01 \mathrm{M}$ phosphate-buffered saline (PBS), $\mathrm{pH}$ 7.4. They were kept at $4{ }^{\circ} \mathrm{C}$ in the dark overnight and then transferred into fresh PBS $0.01 \mathrm{M}$. For orientation purposes and to facilitate the penetration of fixative to the retina, a hole was made in the nasal pole of the ora serrata using a 25-gauge needle before removal. Eyes were dissected under a binocular dissecting microscope; cornea, lens, and vitreous were removed. For sectioning, eyecups were bisected by cutting with a clean scalpel blade, running through the optic nerve head $(\mathrm{ONH})$ along a superior to inferior axis (using the nasal hole as a reference). Routine histologic examination was performed on paraffin wax-embedded eyes using standard procedures. Deparaffinized sections were briefly washed in distilled water and stained with Mayer's or Carazzi's hematoxylin $6.67 \mathrm{mg} / \mathrm{L}$ solution for 5 minutes, followed by counterstaining with eosin $(0.25 \%$ in acetic acid $0.16 \%)$ for 30 seconds. For frozen sections, hemisected eyeballs were cryoprotected in an ascending gradient of sucrose solutions $(10 \%, 20 \%$, and $30 \%)$, then embedded in compound (Tissue-Tek O.C.T.; Sakura Finetek Europe, Zoeterwoude, The Netherlands) and frozen in liquid nitrogen. Frozen sections $(10 \mu \mathrm{m})$ were made using a cryostat (CM3050 S; Leica Instruments, Heidelberg, Germany), mounted on gelatin-coated glass slides, and kept at $-20^{\circ} \mathrm{C}$ until needed for histologic staining. Sections were taken in a systematic manner along the vertical meridian at $275-\mu \mathrm{m}$ intervals, extending from the $\mathrm{ONH}$ in both nasal and temporal directions.

Immunohistochemistry was performed on sections permeabilized with $0.1 \%$ Triton $\mathrm{X}-100$ for 5 minutes and then saturated with PBS $0.01 \mathrm{M}, \mathrm{pH} 7.4$, containing 3\% BSA, 0.05\% Tween-20, and $0.1 \%$ sodium azide $\left(\mathrm{NaN}_{3}\right)$ for 30 minutes. ${ }^{28,40}$ The primary antibody was diluted in the saturation buffer and left overnight at $4{ }^{\circ} \mathrm{C}$. Sections were washed three times for 10 minutes with $0.01 \mathrm{M}$ PBS. Secondary antibody incubation was performed at room temperature for 2 hours with goat anti-rabbit or anti-mouse IgG-conjugated antibodies coupled with Alexa 594 or 488, respectively (Molecular Probes Ltd., Eugene, OR; $2 \mu \mathrm{g} / \mathrm{mL}$ ). Cell nuclei were stained with 4,6-diaminophenyl-indolamine (DAPI; Sigma) diluted at 1:500. The sections were again washed three times with PBS $0.01 \mathrm{M}$ and then mounted using a glycerol/PBS solution 1:1 vol/vol.

\section{Antibody Characterization}

Primary antibodies used for immunohistochemistry were monoclonal antirhodopsin, polyclonal anti-cone mid-wavelength (MW) opsin, polyclonal anti-cone arrestin, and polyclonal anti-glial fibrillary acidic (GFAP) antibodies. Antibody data are reported in Table 1 . The four antibodies crossreact specifically with their $A$. ansorgei homologs, as judged by comparative Western blot analysis. ${ }^{28}$

\section{In Situ Cell Death Detection (TUNEL Analysis)}

In our experiments, apoptosis was assessed with a commercial kit (Cell Death Detection Kit; Roche Diagnostics, Basel, Switzerland). The solution mixture was placed on sections in a dark humid chamber at $37^{\circ} \mathrm{C}$ for 1 hour according to the manufacturer's instructions. Sections were then washed twice with PBS and mounted with PBS/glycerol 1:1.

TABle 1. Primary Antibodies

\begin{tabular}{lllcc}
\hline \multicolumn{1}{c}{ Antigen } & Host & Source & Catalog/Clone & Concentration \\
\hline Rhodopsin & Mouse & Robert S. Molday, University of British Columbia, Vancouver, BC, Canada & Rho4D2 & $1 \mu \mathrm{g} / \mathrm{mL}$ \\
MW-cone opsin & Rabbit & Cheryl M. Craft, Doheny Eye Institute, USC, Los Angeles, CA & - & $1 \mu \mathrm{g} / \mathrm{mL}$ \\
Cone arrestin & Rabbit & Cheryl M. Craft, Doheny Eye Institute, USC, Los Angeles, CA & - & $1 \mu \mathrm{g} / \mathrm{mL}$ \\
GFAP & Rabbit & Santa Cruz Biotechnology, Santa Cruz, CA & $\mathrm{sc}-9065$ & $10.25 \mu \mathrm{g} / \mathrm{mL}$ \\
\hline
\end{tabular}




\section{Lipid Analysis}

To determine whether differences in lipid composition could account for the particular nature of $A$. ansorgei retinal tissue, we analyzed the free fatty acid profiles of whole retinas from young age-matched $A$. ansorge $i$ and pigmented Brown Norway rats. Fatty acid analysis was performed on young adult (3-6 months) $A$. ansorge $i$ and pigmented Brown Norway rats, using previously published techniques. ${ }^{44}$ Animals were euthanized, the eyes enucleated, and the neural retina was removed and stored in chloroform-methanol (2:1, vol/vol). Lipids were extracted according to the Folch method ${ }^{45}$ and transesterified using boron trifluoride in methanol according to Morrison and Smith. ${ }^{46}$ Fatty acid methyl esters were analyzed by gas chromatography ( 5890 series II; Hewlett-Packard, Palo Alto, CA) equipped with a split/splitless injector, a flame-ionization detector, and a CPSil88-silica capillary column $(100 \mathrm{~m} \times 0.25 \mathrm{~mm}$ ID, film thickness $0.20 \mu \mathrm{m}$; Varian, Les Ulis, France). The injector and the detector were maintained at $250^{\circ} \mathrm{C}$ and $280^{\circ} \mathrm{C}$, respectively. Hydrogen was used as a carrier gas (inlet pressure, $210 \mathrm{kPa}$ ). The oven temperature was held at $60^{\circ} \mathrm{C}$ for 5 minutes, increased to $165^{\circ} \mathrm{C}$ at a rate of $15^{\circ} \mathrm{C} / \mathrm{min}$, and held for 1 minute, then raised to $225^{\circ} \mathrm{C}$ at a rate of $20^{\circ} \mathrm{C} / \mathrm{min}$ and left at this temperature for 17 minutes. Fatty acid methyl esters were identified by comparison with commercial standards. The data were processed using chromatogra-

\section{A Scotopic single flash}

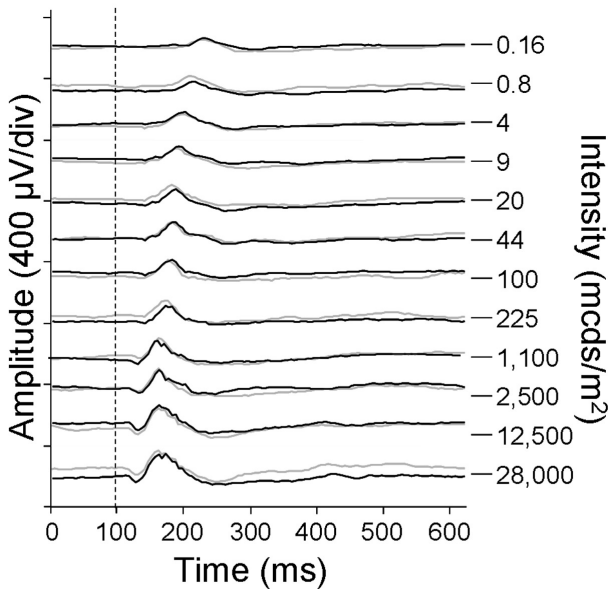

C Photopic single flash

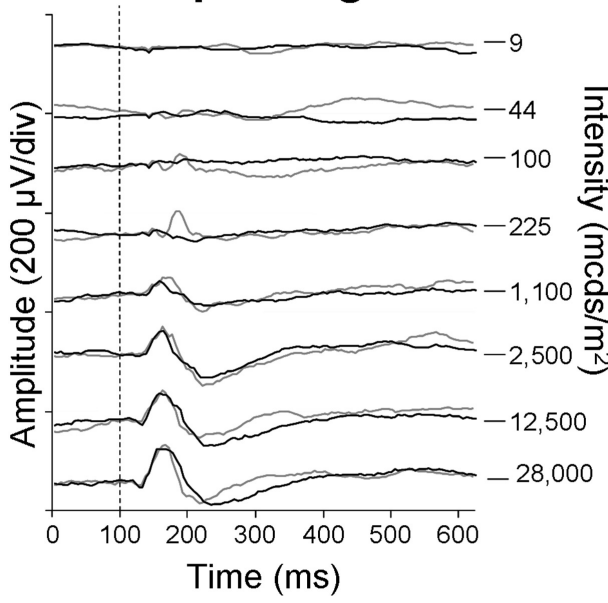

\section{E $6 \mathrm{~Hz}$ flicker, -ILE}

FIGURE 1. Scotopic and photopic single flash and flicker visual responses of unexposed $A$. ansorge $i$ (-ILE, black traces) and A. ansorge $i$ 12 days after exposure (+ILE, gray traces). (A) Single-flash responses under scotopic conditions. (B) Flicker responses under scotopic conditions. (C) Single-flash responses under photopic conditions. (D) Flicker responses under photopic conditions. (A-D) Individual responses. (E) 6-Hz flicker amplitudes from -ILE $(n=6)$. (F) 6-Hz flicker amplitudes from $+\operatorname{ILE}(n=6)$ A. ansorgei, as a function of the logarithm of flash intensity.

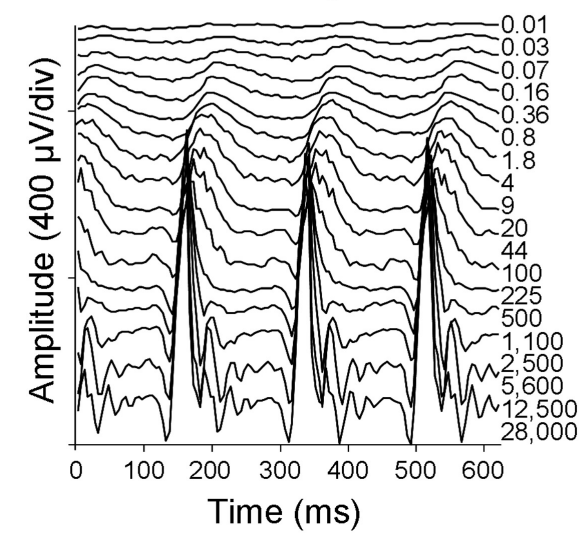

\section{B Scotopic flicker}

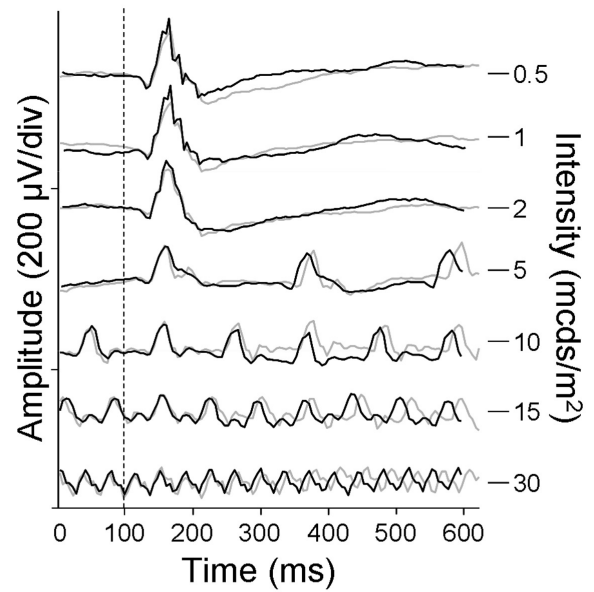

\section{Photopic flicker}

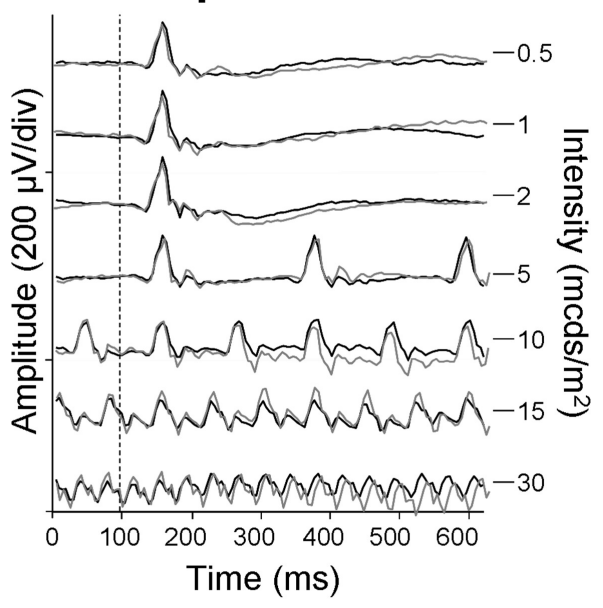

\section{F $6 \mathrm{~Hz}$ flicker, +ILE}

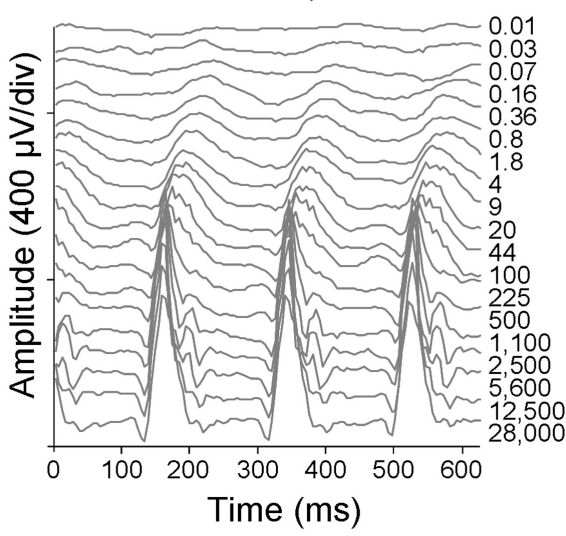


phy data software (EZChrom Elite; Agilent Technologies, Massy, France) and were expressed as a percentage of total fatty acids. Results were presented as mean $\pm \mathrm{SD}$. The Kruskal-Wallis test was used to compare the data from $A$. ansorge $i$ and pigmented Brown Norway rats using SAS software (SAS Institute, Cary, NC). $P<0.05$ was considered statistically significant.

\section{ResUlTS}

\section{Electroretinography of -ILE $A$. ansorgei Compared with Other - ILE Rodent Species}

Compared with C57BL/6 mice, the rod contribution of the dark-adapted scotopic response was reduced [absence of maximal rod response at $10 \mathrm{mcd} \cdot / \mathrm{m}^{2}(\log (\mathrm{I})=-2.0)$, and the negative a wave was elicited at intensities $>100 \mathrm{mcd} \cdot / \mathrm{m}^{2}$ $(\log (\mathrm{I})=-1.0)]$ (data not shown). Concordant with the cone-rich composition of their retinas, visual responses were dominated by cones, as illustrated by the characteristic triangular shape of dark-adapted scotopic responses (Figs 1A, 1B) and the amplitudes of 6-Hz flicker responses at high light intensities (Figs. 1E, 1F). Finally, global comparison of $6-\mathrm{Hz}$ flicker responses in A. ansorgei ( \pm ILE) and mice ( - ILE) confirmed the cone-dominated visual response in the former (Fig. 2E). It should be noted that although the rod sensitivity peak was similar between $A$. ansorge $i$ and $M$. musculus (at $\log (\mathrm{I})=-1.7)$, that for cones was shifted to the left in $A$. ansorgei $(\log (\mathrm{I})=0.75)$ and out of range for $\mathrm{C} 57 \mathrm{BL} / 6$ mice (Fig. 2E), suggesting that $A$. ansorgei cone photoreceptors are more sensitive to light stimulation.

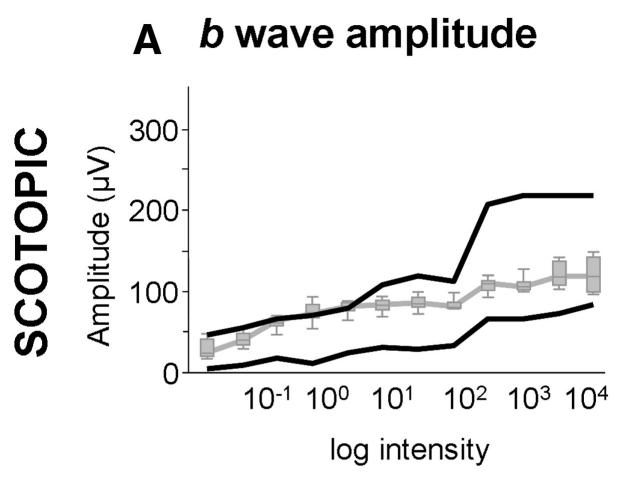

C b wave amplitude
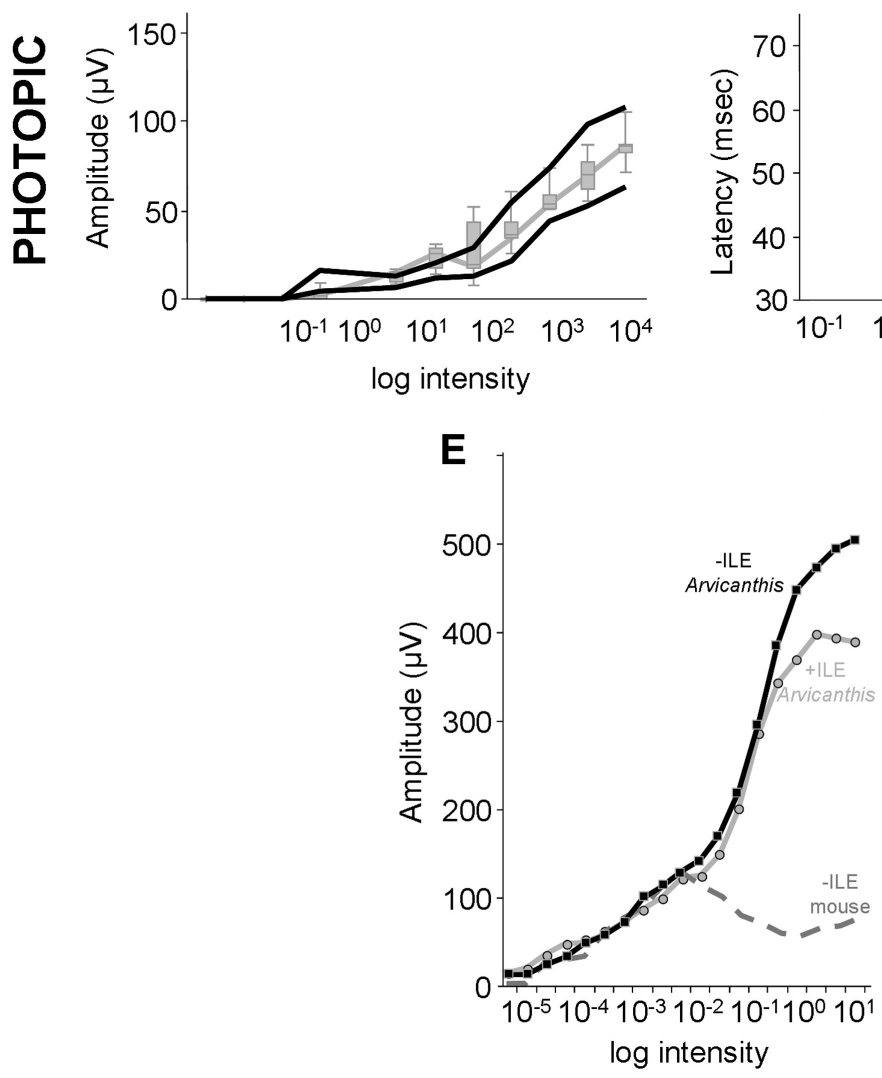

Figure 2. Mean average b-wave amplitudes and latencies for scotopic and photopic visual responses from -ILE A. ansorgei ( $n=6$, solid black lines), + ILE $A$. ansorge 1 week after exposure ( $n=6$, solid gray line), and - ILE C $57 \mathrm{BL} / 6$ mouse $(\mathbf{E}, n=1$, dotted black line). (A-D, boxes) 25\% to $75 \%$ quantile range. Bars indicate the $5 \%$ and $95 \%$ quantiles, and the central gray bar indicates the median of the +ILE $A$. ansorge $i$ data. The black lines delimit the normal range given by the $5 \%$ and $95 \%$ quantiles of -ILE animals. NSD between -ILE and + ILE $A$. ansorgei. NSD for b-wave amplitudes (A) and latencies (B) between either group under scotopic illumination. NSD for photopic b-wave amplitudes (C) between groups, but there is an increase in b-wave latencies at photopic stimulus intensities $<\mathrm{mcd} \cdot \mathrm{s} / \mathrm{m}^{2}$, as seen by the displacement of the gray trace to values lying above the normal range (D). (E) Comparison of b-wave amplitudes obtained at $6-\mathrm{Hz}$ flicker frequencies for -ILE and +ILE $A$. ansorge $i$ and -ILE C57BL/6 mice. ILE did not affect rod and cone sensitivities to light in $A$. ansorge $i$ -ILE. +ILE A. ansorge i display similar rod sensitivity to light compared with - ILE C57BL/6 mice, $\log (\mathrm{I})=$ -1.7 ), whereas the sensitivity of cones to light is increased in $A$. ansorgei $(\log (\mathrm{I})=0.75)$ compared with C57BL/6 mice. 


\section{No Damage in $A$. ansorgei Retina from a Single Intense Light Exposure}

Figure 1 depicts typical recordings of individual - ILE and + ILE $A$. ansorgei under dark-adapted single flash (Fig. 1A), darkadapted flicker (Fig. 1B), light-adapted single flash (Fig. 1C), light-adapted flicker (Fig. 1D), and 6-Hz flicker for - ILE (Fig. 1E) and +ILE (Fig. 1F) $A$. ansorgei, respectively. The darkadapted scotopic responses did not show any major differences between -ILE and +ILE $A$. ansorge $i$ either for latencies or for amplitudes (Figs. 1, 2). A small delay was seen for scotopic and photopic flicker ERGs at frequencies higher than $5 \mathrm{~Hz}$, but amplitudes remained similar between both groups (Figs. 1B, 1D). Similarly, there were no large differences between the two groups for photopic responses (again a small delay in response onset in +ILE $A$. ansorge $i$, but only at the highest frequency tested in photopic flicker; Fig. 1D). When responses were averaged from all individual $A$. ansorge $i$ per group, it can be seen that latency and amplitude means for scotopic and photopic responses in +ILE $A$. ansorge $i$ fell within the 90 percentile range for - ILE responses (Figs. 2A2C). A difference was noted for the b-wave latency under the photopic protocol at low intensities, but this difference disappeared when intensity increased (Fig. 2D). Finally, comparison of $6-\mathrm{Hz}$ flicker responses showed there was no significant difference between -ILE and +ILE A. ansorgei (Fig. 2E).

\section{No Damage to $A$. ansorgei Retina from Higher or Longer Intensity Light Exposures}

As seen previously, no damage was apparent after a 6 klux ILE of 8 hours. In addition, none of the +ILE $A$. ansorgei retinas exposed for 2-hour ILE of 12 klux showed any structural or morphologic changes compared with - ILE retinas. There was no apparent shortening of outer segments (OS) or any nuclear condensation or change in protein expression or distribution (Fig. 3). Although the retina of $A$. ansorgei was not affected under these conditions, the same treatment in 12956 pigmented mice led to severe loss of the ONL (Figs. 4C, 4D). No TUNEL staining was seen on sections of + ILE retinas taken 36 hours after exposure to 15 klux light for 8 hours, whereas retinal sections of albino Balb/c mice exposed to 5 klux for 1 hour showed widespread apoptotic nuclei (Figs. 4E-G). Moreover, there was no overexpression of GFAP in any case (data not shown). Increasing the light intensity to 20 klux did not reveal any damage when examined at 10 days after exposure, and no structural damage was seen in any of the + ILE retinas (not shown). A. ansorgei exposed at 5 klux continuously for 1
FIGURE 3. Immunohistochemical labeling of rod and cone photoreceptors in $A$. ansorge $i$ - ILE and +ILE retinas. (A-C) - ILE animal (C, $n=1)$. (D-F) + ILE animal exposed to 5 klux for 120 minutes $(n=1)$. (G-I) +ILE animal $(n=1)$ exposed to 12 klux for 120 minutes. (A, D, G) DAPI staining reveals the normal three-cell layer organization in all conditions. (B, E, H) Antirhodopsin labeling shows only rod OS staining in all three conditions. (C, F, I) Cone MW opsin immunostaining is always restricted to the cone OS. Scale bar, $40 \mu \mathrm{m}$.
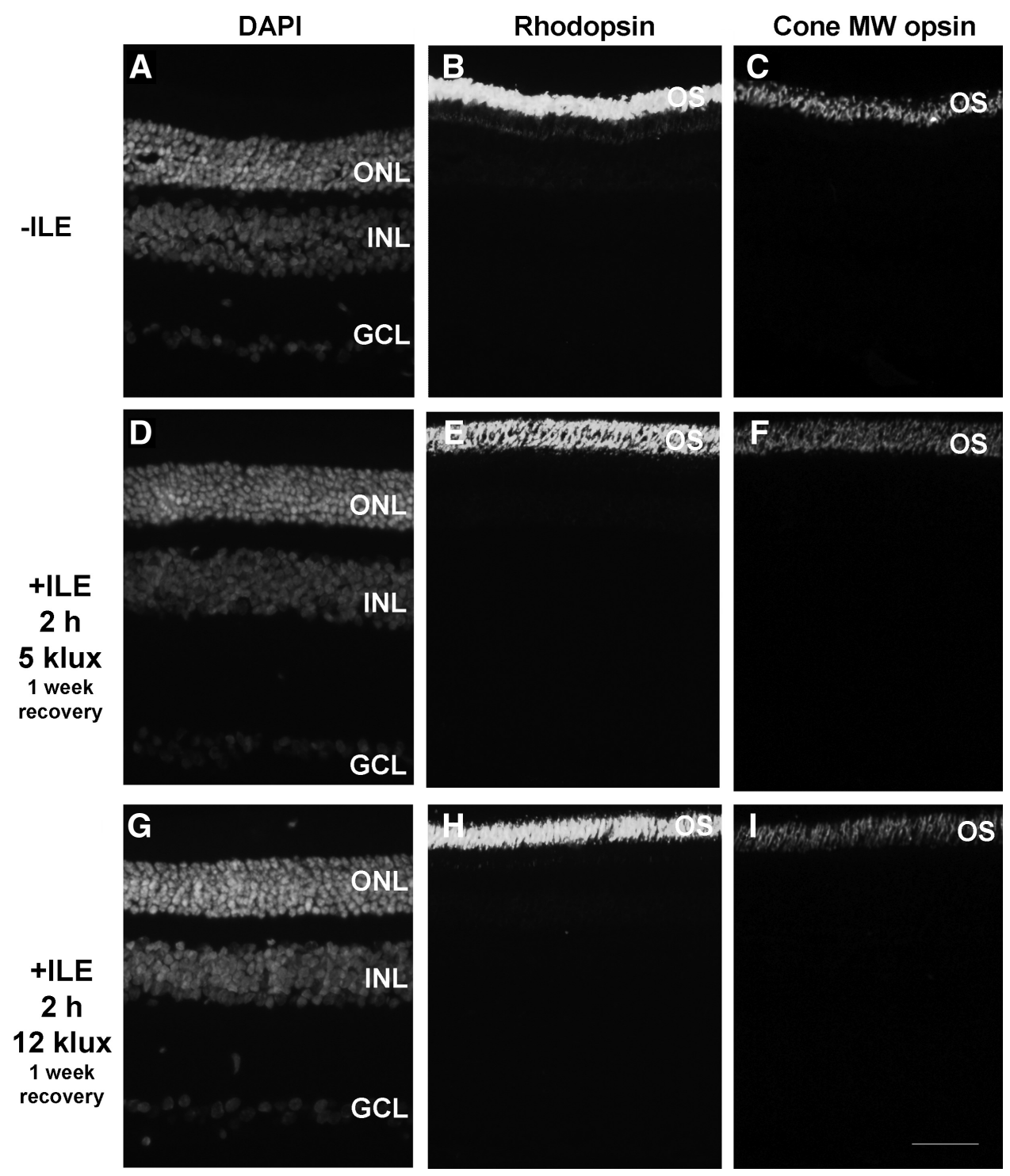

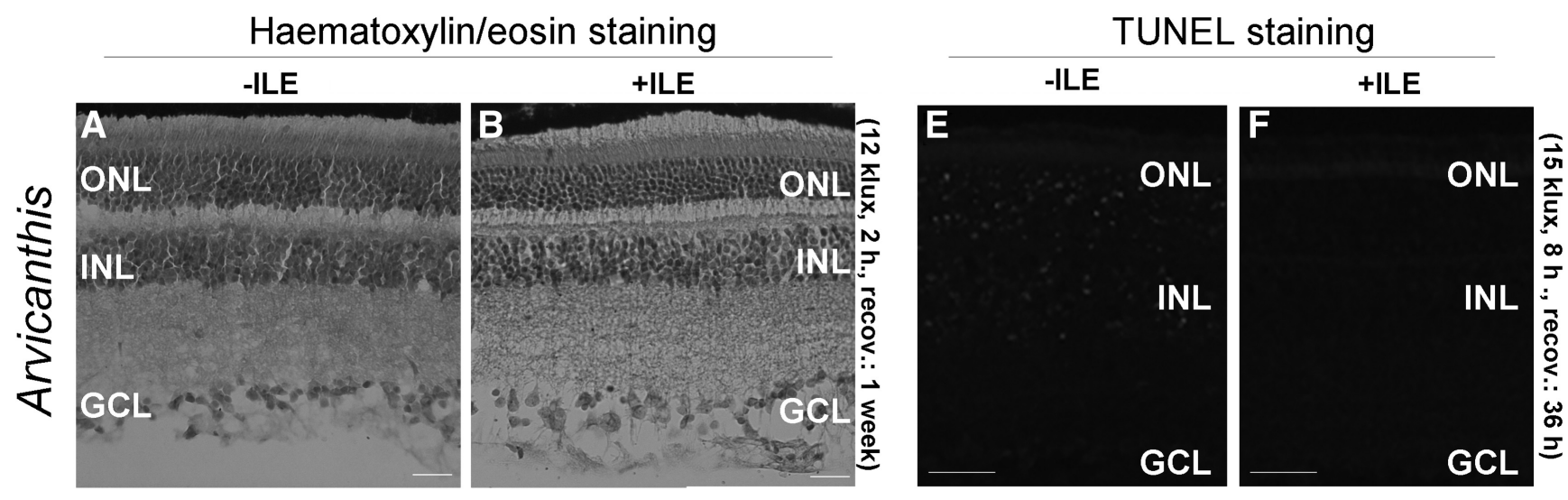

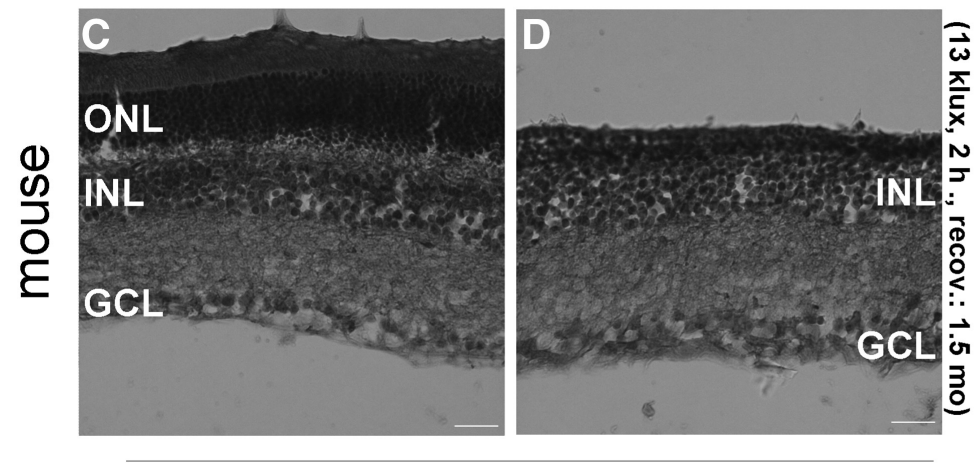

pigmented mouse (129S6)

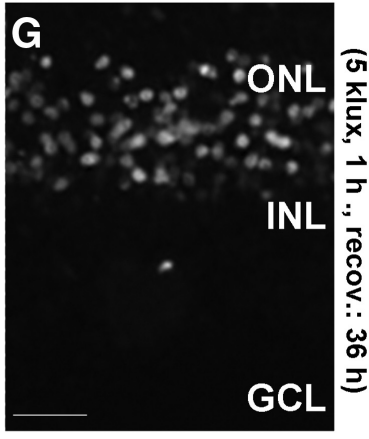

albino mouse

$(B A L B / c)$

FIGURE 4. ILE does not elicit apoptosis in A. ansorgei photoreceptors but is injurious for albino and pigmented mice photoreceptors. (A-D) Hematoxylin and eosin staining. (A) - ILE A. ansorgei retina $(n=1)$. (B) A. ansorgei retina after 2-hour ILE at 12 klux $(n=1)$. The structure of the $A$. ansorgei retina was not affected by the exposure. $(C)$-ILE pigmented mouse $(12956)$ retina $(n=3)$. (D) Pigmented mouse $(12956)$ retina after 2-hour ILE at $13 \mathrm{klux}(n=6)$. There was complete loss of the ONL after light exposure. (E) -ILE A. ansorgei (F) +ILE A. ansorgei retinas taken 30 hours after exposure to 15 klux white light for 8 hours. No TUNEL reaction is seen in either case. (G) Retinal sections of albino Balb/c $(n=6)$ mice exposed to 5 klux for 1 hour (hence, 24 times less total light) already show widespread apoptotic nuclei within the ONL. Scale bar, $50 \mu \mathrm{m}$.

week and euthanized 36 hours later did not show structural changes (not shown).

\section{No Damage to $A$. ansorgei Retinas Based on Circadian Rhythm}

+ILE A. ansorgei retinas showed no differences compared with - ILE tissue as revealed by classical histology or rhodopsin and MW opsin immunostaining. Even though restricted areas could show higher expression of the markers (Fig. 5), overall expression of the proteins was the same between day- and night-exposed groups. Moreover, no positive TUNEL staining was seen in any $A$. ansorgei retinas (data not shown).

\section{No Damage to $A$. ansorgei Retina Based on Light-Rearing History}

Sections made from dim light- or standard LD-reared retinas did not show any differences in overall structure or expression of rod and cone markers (Fig. 6).

\section{Focal Damage to $A$. ansorgei Retina from Prolonged Intense Blue Light}

Only retinas of $A$. ansorgei exposed for 45 minutes showed some localized degeneration, visible as a discrete spot approximately 1 to $2 \mathrm{~mm}^{2}$ in the central retina. Within this area, there was complete destruction of all three cell layers, as seen by hematoxylin and eosin and DAPI staining (Figs. 7A-C). Expression of rhodopsin, cone arrestin, and GFAP was also investi- gated in these retinas. Retinas exposed for 5 and 15 minutes showed normal expression and distribution of both photoreceptor markers, as did the 45-minute blue ILE retina outside the lesion site. In the latter, at the level of the injury, there was complete disappearance of photoreceptor markers (Figs. 7D, 7E). In addition, whereas GFAP expression was restricted to astrocytes in the nerve fiber layer in 5- and 15-minute blue +ILE A. ansorgei retinas (Figs. 7F, 7G; similar to controls), the 45-minute blue + ILE individual exhibited upregulation of GFAP expression across the retina (Fig. $7 \mathrm{H}$ ).

\section{No Damage to $A$. ansorgei Retina from Standard Doses of MNU}

In an initial series, A. ansorgei were injected with $75 \mathrm{mg} / \mathrm{kg}$ MNU based on published values. Albino Wistar and pigmented Long-Evans rats were injected with the same dose, and all animals were euthanized 9 and 20 days postinjection (d.p.i). After 9 dpi, MNU-treated rat retinas (both albino and pigmented) were greatly affected, and the ONL was completely absent as judged by histology, DAPI staining, and absence of PR protein expression (Figs. 8E-H). The same features were observed at $20 \mathrm{dpi}$ (data not shown). In contrast, MNU-treated $A$. ansorgei retinas did not show any difference with respect to vehicle-injected controls at 9 or $20 \mathrm{dpi}$ with respect to cell number, tissue morphology, or phenotypic expression (Figs. 8M-P, 20 dpi). 


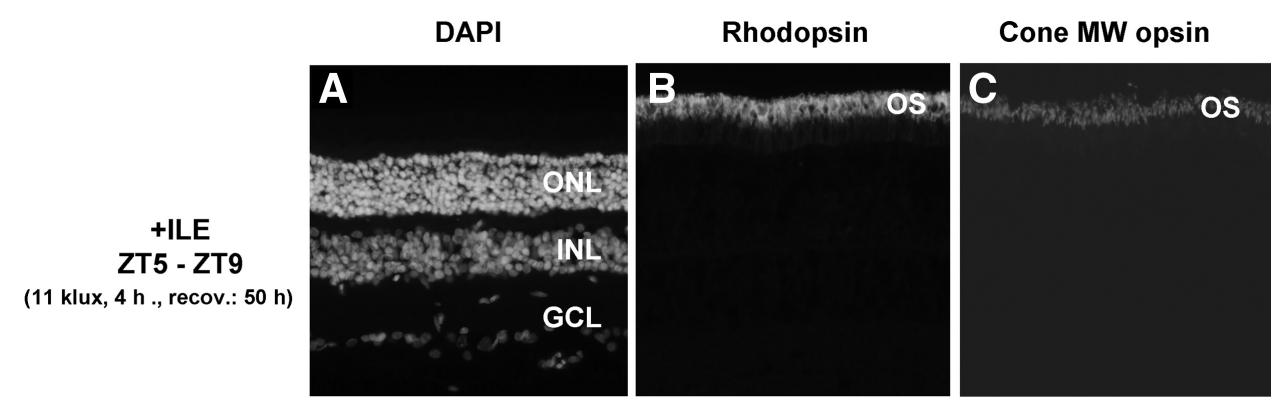

FIGURE 5. A. ansorgei exposed for 4 hours at 11 klux white light at different circadian times. (A-C) A. ansorgei exposed at ZT5 (12 AM) $(n=2)$. (D-F) $A$. ansorgei exposed at ZT17 (12 PM) $(n=$ 2). Animals were killed 50 hours after exposure. NSD between + ILE and - ILE $(n=1)$ retinas as revealed by DAPI staining (A, D), rhodopsin (B, E), and cone MW opsin (C, F) immunostaining. Scale bar, $50 \mu \mathrm{m}$.

(11

\section{Regional Damage to $A$. ansorgei Retina from Elevated Doses of MNU}

In a second set of experiments, $A$. ansorge $i$ were injected with higher doses of MNU (100 and $150 \mathrm{mg} / \mathrm{kg}$, respectively), and the effects were analyzed at the structural level. To measure the temporal progression of induced degeneration, we performed quantitative morphometry on retinal sections from $A$. ansorge $i$ killed at 3, 5, 8, 11, 15, and 20 dpi after a 150-mg/kg MNU injection. Sections were obtained at the midperiphery from both the inferior and the superior hemispheres. Compared with similar sections from vehicle-injected $A$. ansorgei
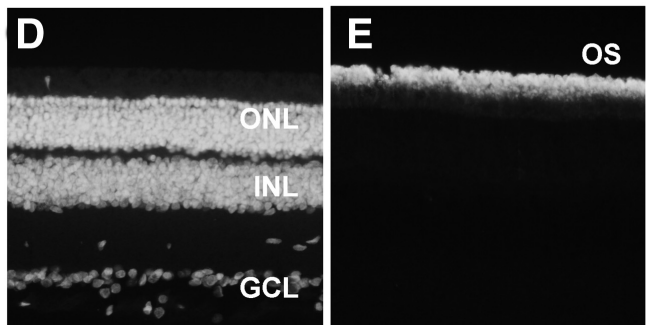

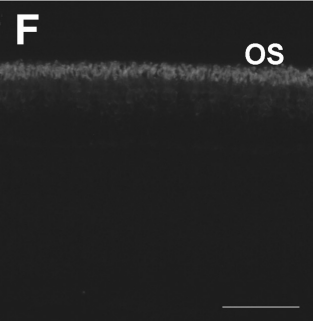

retinas (Figs. 9A, 9B), there were no apparent modifications until 8 dpi (Figs. 9C-H). Thereafter, there was a gradual thinning of the outer retina (OS plus ONL) visible by $11 \mathrm{dpi}$ within the superior but not the inferior retina (Figs. 9I, 9J). By 15 dpi, the superior ONL was reduced to just two cell rows and the OS were no longer present, whereas the inferior retina also started to show signs of mild disruption (shortened OS, disorganized ONL) (Figs. 9K, 9L). By the latest period examined (20 dpi), the superior ONL was highly degenerated and the inferior retina showed moderate breakdown with shortened OS and two to three cell rows within the ONL (Figs. 9M, 9N). The other cell
FIGURE 6. Light-rearing history does not affect light damage in A. ansorgei. (A-C) Animals were reared in LD cycles with dim light (low, 20 lux), or (D-F) normal room light (high, 300 lux) for 4 weeks before 8-hour exposure at 13 klux. None of the +ILE retinas $(n=6)$ show differences between each other or compared with - ILE retinas $(n=6)$ as revealed by DAPI staining $(\mathbf{A}, \mathbf{D})$, rhodopsin $(\mathbf{B}, \mathbf{E})$, and cone $\mathbf{M W}$ opsin $(\mathbf{C}, \mathbf{F})$ immunostaining. Scale bar, $40 \mu \mathrm{m}$.
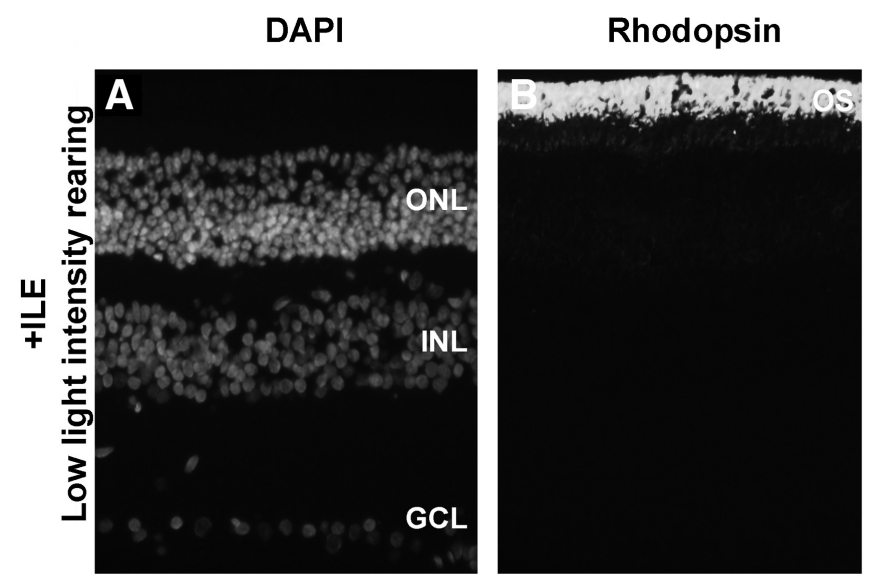

\section{Cone MW opsin}
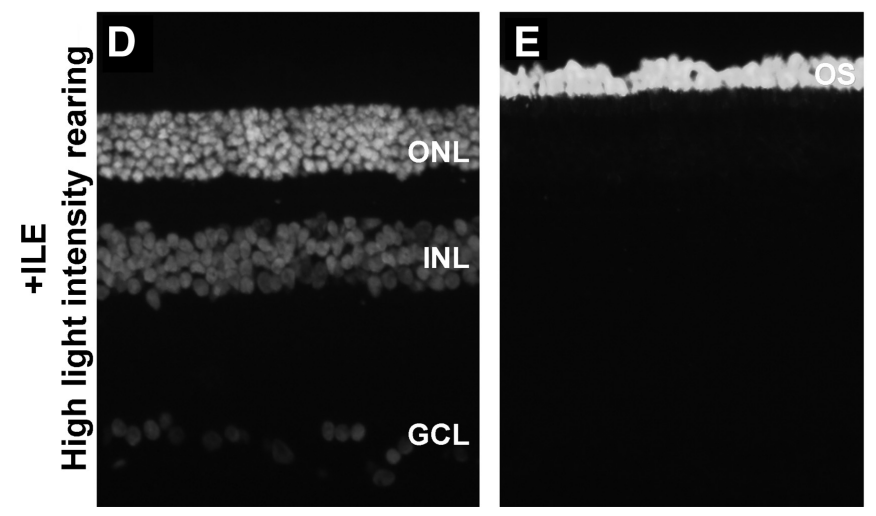
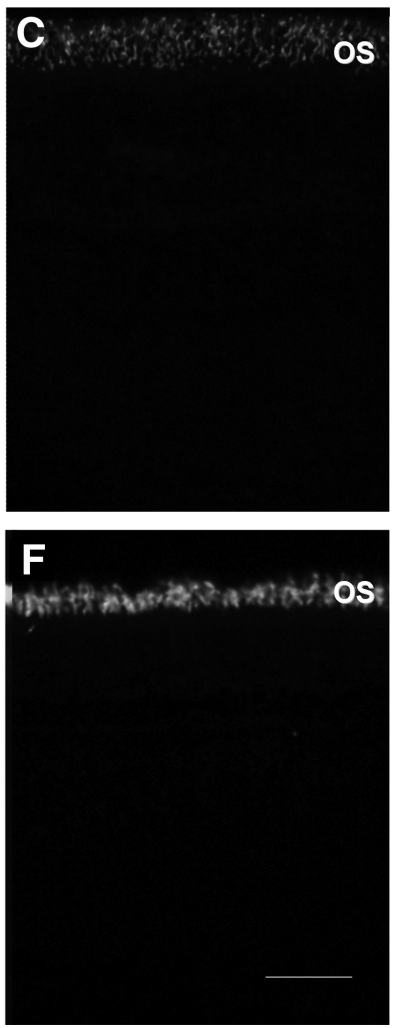

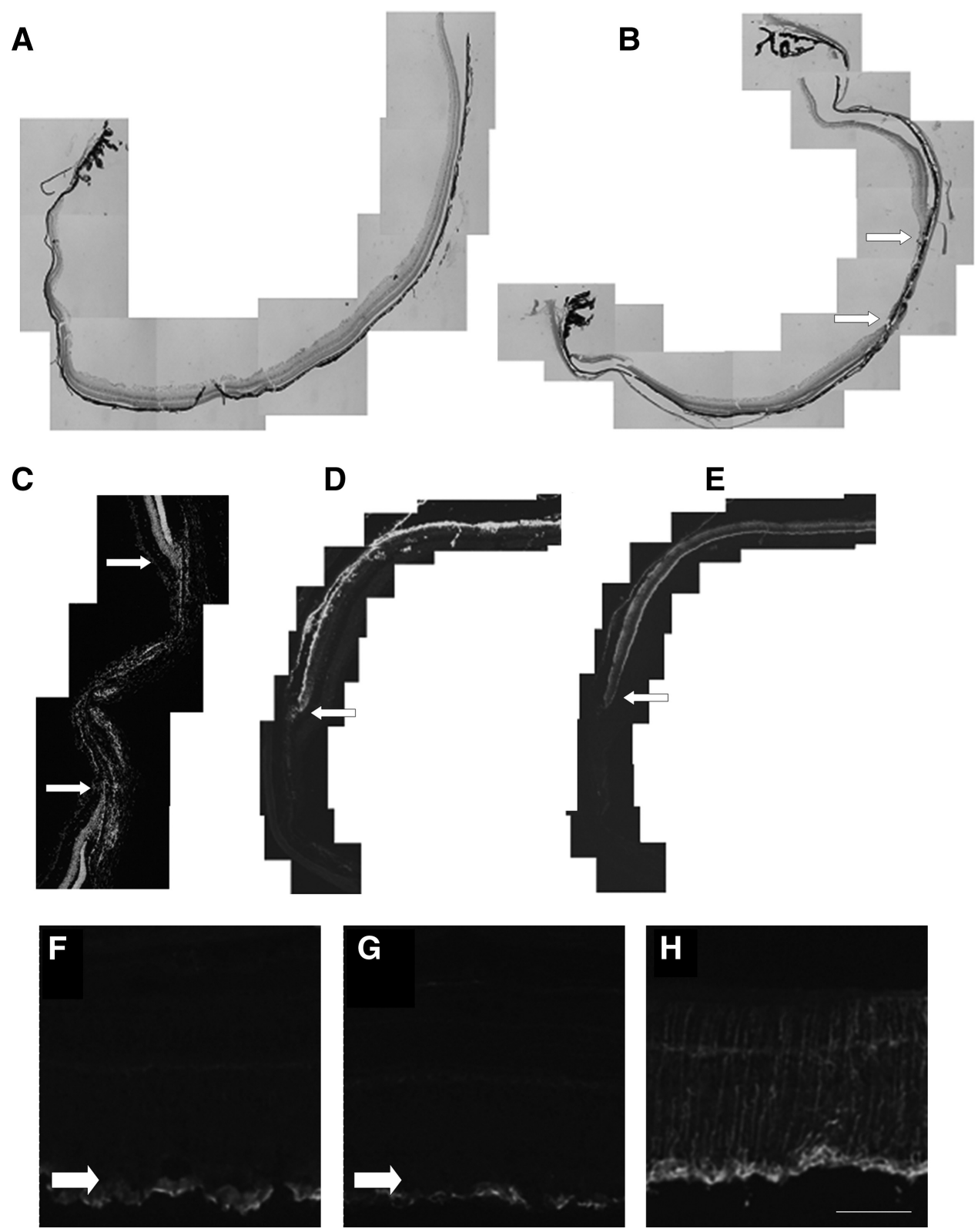

Figure 7. Long exposures to intense blue light led to focal lesions of $A$. ansorgei neural retina. Animals were exposed to (A) 15 minutes $(n=3)$ and (B) 45 minutes $(n=1)$ of intense blue light $\left(30 \mathrm{~mW} / \mathrm{cm}^{2}\right.$, $410 \mathrm{~nm}$ ) and were killed 10 days later. Retinal histology was normal 10 days after 15-minute exposure to blue light, whereas a $\sim 1$-mm-diameter circular lesion was observed 10 days after 45-minute exposure (arrows, B). (C) Higher magnification of 45 minutes by DAPI staining (arrows). (D) Rhodopsin (arrow) and (E) cone MW opsin (arrow) immunolabeling stops abruptly at the level of the lesion. (F-H) GFAP staining provides an indicator of general retinal stress. At 5 minutes (F) and 15 minutes (G), it was confined to retinal astrocytes (arrows), whereas in 45 minute-exposed retinas there is generalized radial staining across the width of the retina $(\mathbf{H})$. Scale bars: $300 \mu \mathrm{m}(\mathbf{A}, \mathbf{B}) ; 100 \mu \mathrm{m}(\mathbf{C}-\mathbf{E})$; $50 \mu \mathrm{m}(\mathbf{F}-\mathbf{H})$.

layers, inner nuclear layer (INL), and ganglion cell layer (GCL) were less affected by MNU injection, but there was also loss in INL thickness within the superior retina after $15 \mathrm{dpi}$. None of the vehicle-injected $A$. ansorge $i$ killed at the end of the experiment exhibited any structural changes of the retina.

We examined retinas from vehicle- and MNU-injected (20 dpi) A. ansorgei for the presence and distribution of apoptotic cells. TUNEL-stained sections from the midperipheral superior retina revealed numerous positive profiles (Fig. 10A), whereas sections from the corresponding midperipheral inferior retina showed apoptotic profiles uniquely at the level of the rod photoreceptor cell bodies, in the vitrealmost rows of the ONL (Fig. 10B). Control retinas showed no TUNEL staining in any layer (not shown). To determine whether rods and cones could still be identified within these zones, immunohistochemistry was performed on similar sections. In accordance with the TUNEL data, superior retinal sections showed severe thinning of the ONL (Fig. 10C), very reduced staining of rods (Fig. 10D), and reduced staining of cones (Fig. 10E) compared with the same images from the inferior retina (Figs. 10F-H). It should be noted that the reduction in rod immunolabeling was much greater than that for cones, indicating the preferential degeneration of rods.

\section{Free Fatty Acid Profiles of $A$. ansorgei Compared with Pigmented Rats}

Table 2 presents the data from fatty acid analyses of $A$. ansorge $i$ and Brown Norway rats. In terms of statistically significant differences, the whole rat retina contained approximately $8 \%$ less saturated fatty acids (39.33 vs. $42.4 \%$ of total fatty acids; $P=0.002$ ), approximately $22 \%$ more monounsaturated fatty acids ( 14.38 vs. $11.75 \%$ of total fatty acids; $P=0.001)$, and approximately $8 \%$ more dimethyl acetal (DMA) (6.50 vs. $6.07 \%$ of total fatty acids; $P=0.004)$ than the $A$. ansorge $i$ retina. In contrast, $A$. ansorge $i$ retinas contained approximately $14 \%$ more DHA than Brown Norway rats $(26.11 \%$ vs. $22.60 \%$ of total fatty acids; $P=0.001)$. There were no significant differences in the whole retina content of polyunsaturated fatty acids. 
Figure 8. Injection of standard doses of MNU does not induce PR degeneration in A. ansorgei. (A-D) Pigmented Long-Evans rats injected with vehicle buffer only $(n=2)$. (E-H) Long-Evans rats receiving intraperitoneal injection of MNU (75 $\mathrm{mg} / \mathrm{kg}$ body weight, $n=2$ ). MNU treatment led to massive and specific loss of the ONL within $9 \mathrm{dpi}$, as seen by conventional histology (hematoxylin and eosin $[H / E], \mathbf{A}, \mathbf{E})$, DAPI staining $(\mathbf{B}, \mathbf{F})$, rhodopsin $(\mathbf{C}, \mathbf{G})$, and cone MW opsin $(\mathbf{D}, \mathbf{H})$ staining. On the other hand, (I-L) vehicle-injected $(n=6)$ and (M-P) MNU-injected $(n=6)$ A. ansorgei were similar, with no discernible ONL degeneration. Scale bar, $40 \mu \mathrm{m}$. IPL, inner plexiform layer.
$H / E$

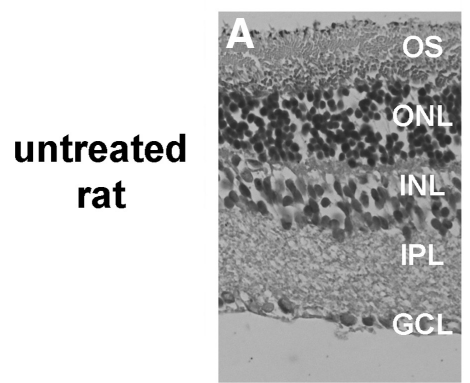

MNU

rat

9 d.p.i.

\section{untreated Arvicanthis}
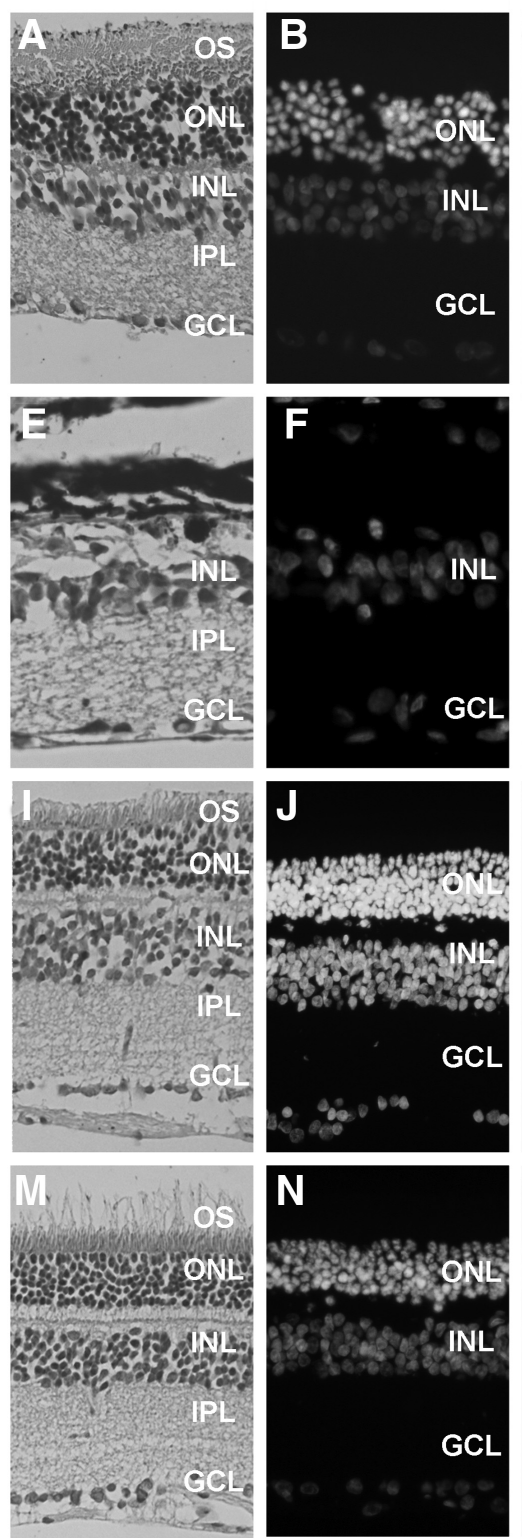

Rhodopsin
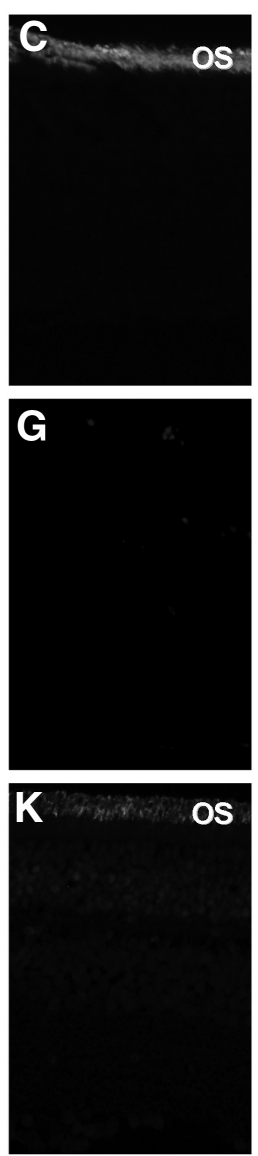

Cone MW opsin
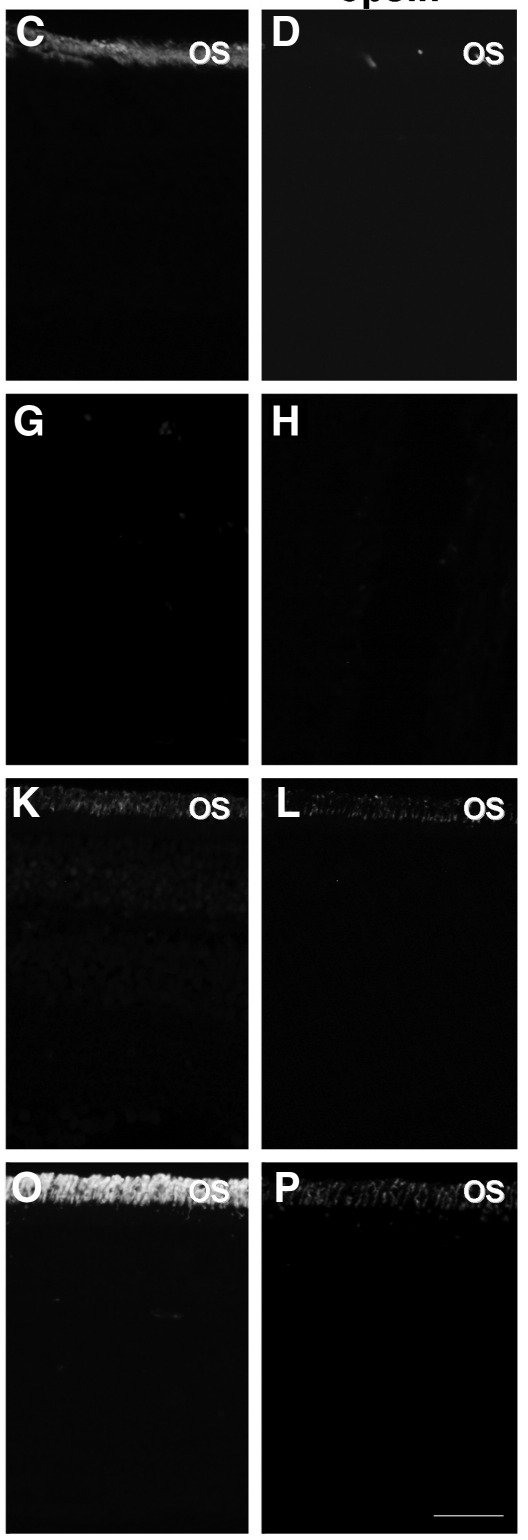

\section{Discussion}

Within the context of human blinding diseases, environmental factors are incriminated as playing detrimental roles in their own right or as increasing the progression and severity of inherited retinal disorders. Phototoxicity in particular has been used as an experimental model to induce rapid photoreceptor breakdown, and the molecular mechanisms involved in the degenerative process have been well characterized. However, the pertinence of experimental observations largely obtained using albino nocturnal rodents is still unresolved. In the present study, we examined induced retinal degeneration in a pigmented diurnal rodent, $A$. ansorgei. In contrast to the principally nocturnal members of Mus and Rattus genera, $A$. ansorgei and many other African rodents (Lemniscomys, Psammomys) are active in the daytime. Nocturnal $M$. musculus and $R$. norvegicus rely on rod-mediated vision, and rods compose $97 \%$ and $98 \%$ total photoreceptors, respectively. ${ }^{29,30}$ In seeking animal models that would facilitate research into cone pathophysiology, we reasoned that diurnal types might have greater numbers of cones because these cells subserve daylight vision. This was indeed the case because immunohistochemical and histologic analyses revealed more than 10-fold higher cone numbers in $A$. ansorgei. ${ }^{28,31,47}$ They are recognized by a range of antibodies raised against murine cone proteins, such as cone SW and MW opsin, cone arrestin, ${ }^{28}$ and cone transducin. ${ }^{31}$ Importantly, we have established a viable captive colony of this species, enabling systematic experimentation of their physiology and behavior. ${ }^{32}$ In the current context, this species demonstrated an almost total resistance to light damage, despite the use of conditions many fold higher than those known to induce complete breakdown in albino and pigmented rats and mice. Furthermore, this resistance was not unique to light damage; there was also no visible degeneration after the injection of standard doses of the toxic drug MNU, which is known to induce photoreceptor death. These findings, therefore, caution against the straightforward extrapolation of experimental data from nocturnal species to humans. 


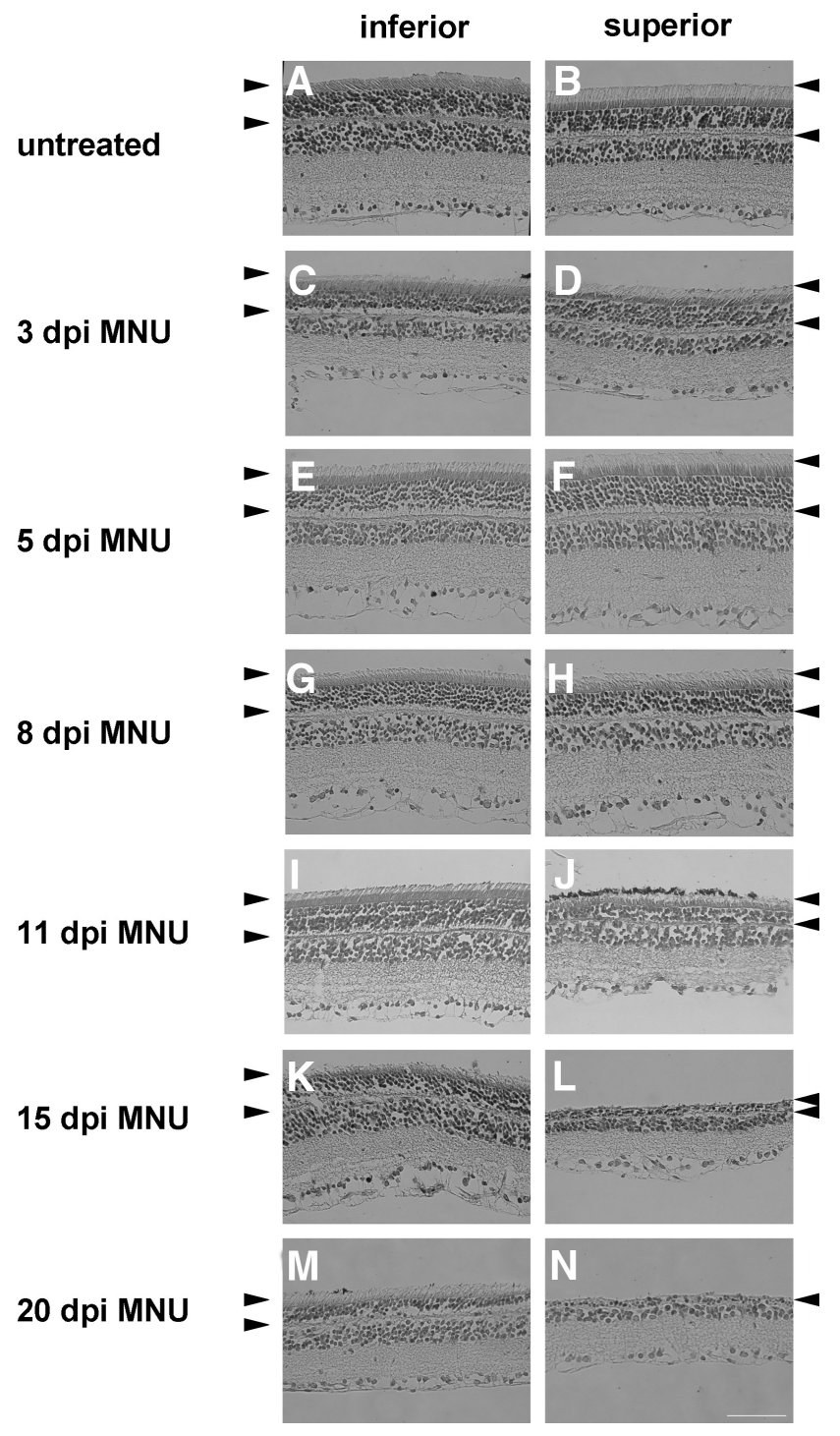

FIGURE 9. Injection of elevated doses of MNU induces progressive partial photoreceptor degeneration in A. ansorgei. Adult A. ansorgei were injected with elevated doses $(150 \mathrm{mg} / \mathrm{kg}$ body weight) and killed at regular intervals from 3 to $20 \mathrm{dpi}(n=3$ for each dpi). Sections were obtained at the midperiphery ( $\sim 2 \mathrm{~mm}$ from the optic nerve head) in both the superior and the inferior hemispheres and were stained with hematoxylin and eosin. Paired black markers: thickness of the outer retina, from the distal tip of the OS (upper mark) to the outer plexiform layer (lower mark). (A, B) Control sections, (C, D) 3 dpi, (E, F) $5 \mathrm{dpi}$, and (G, H) $8 \mathrm{dpi}$ all appear similar. (I) At $11 \mathrm{dpi}$, the inferior retina still appears normal, whereas $(\mathbf{J})$ the superior quadrant is markedly thinner. (K) By 15 dpi there is still a normal structure of the inferior retina but (L) severe thinning of the superior retina. (M) At 20 dpi, the inferior retina also shows signs of decreased thickness. (N) The superior retina is reduced to a single cell layer. The INL and GCL are not affected in the inferior retina throughout the course of the observations, whereas the superior retina also shows signs of a thinned INL at $15 \mathrm{dpi}$ and later. Scale bar, $100 \mu \mathrm{m}$.

Light damage to the retina has been documented extensively during the past four decades, ever since Noell et al. ${ }^{48}$ showed that relatively low-intensity illumination led to photoreceptor degeneration in albino rats. ${ }^{48}$ Early studies by Noell et al., ${ }^{48}$ Kaitz and Auerbach, ${ }^{49}$ and Williams and Howell ${ }^{14}$ all pointed to rhodopsin bleaching as the trigger for retinal light damage. Both rhodopsin and RPE65 knockout mice are protected against light damage. ${ }^{39,50}$ Studies have shown the criti- cal importance of rhodopsin regeneration rates within the visual cycle: protection against light damage is seen in mice strains expressing polymorphic variants of RPE65 in which ${ }^{48}$ rhodopsin regenerates less rapidly, ${ }^{51}$ and slowing rhodopsin regeneration with 13-cis retinoic acid prevents light damage in the rat. ${ }^{17}$ The positive correlation between rhodopsin levels and the degree of light damage suggests one possible reason for $A$. ansorgei resistance to photic stress. The "cone-enriched" $A$. ansorgei retina is automatically "rod-poor" compared with rats and mice, and absolute rhodopsin levels per retina are reduced (see Fig. $3{ }^{28}$ for quantitative measures). Hence, there may be some critical threshold value necessary to trigger widespread tissue damage, which is not attainable in the diurnal rodent. However, if this is the case, it indicates that rhodopsin levels are also key in the pathogenic mechanisms underlying MNU toxicity. MNU-induced cell death entails alkylation of $\mathrm{DNA}^{20}$ and excessive activation of NF- $\kappa \mathrm{B} /$ poly (ADP ribose) polymerase. ${ }^{40}$ One common feature between light- and MNU-induced photoreceptor loss is NF- $\kappa \mathrm{B}$ signaling, which may exhibit differences between nocturnal rodents and $A$. ansorgei retina. A further shared characteristic in both paradigms is apoptotic death, ${ }^{23,11}$ so there may be differences in these pathways in the $A$. ansorge $i$ retina.

We based our initial MNU injections on the doses reported in the literature for the induction of specific and massive photoreceptor degeneration in mice ${ }^{21,52}$ and rats ${ }^{20,53}$ (range, $60-75 \mathrm{mg} / \mathrm{kg}$ ). In every reported case, these concentrations led to rapid and quasi-total destruction of the ONL. A. ansorgei were entirely refractory to such treatments, as assessed by histologic, immunohistochemical, and TUNEL analyses at up to 20 dpi. Significantly higher doses were required to produce damage, and this was neither rapid nor complete. MNU treatment is not affected by pigmentation; it is also toxic for pigmented hamster retinas ${ }^{22}$ and Long-Evans rats (present study). The contrasting appearance of the superior and inferior hemispheres after the injection of high doses of MNU recalls the appearance for light damage: moderate light damage results in less damage in the inferior hemisphere than in the superior hemisphere or is absent altogether. Regional differences in photoreceptor ILE damage have been reported by several groups. ${ }^{36,54-56}$ Possible explanations that have been proposed include lower rhodopsin levels within the inferior retina, better intraretinal circulation in the inferior region, or greater neuroprotective factor synthesis. ${ }^{57-59}$ It is thus plausible that this regional difference seen in MNU-injected $A$. ansorge $i$ stems from a "double hit": MNU injection sensitizes the retina at a subthreshhold level, and then reflected light from ceiling lamps tips the balance in favor of degeneration, principally in the superior hemispheres. Such a possibility could be tested by modifying illumination conditions in the animal facilities or by maintaining injected animals on weak cyclic light after MNU treatment.

Many studies show that photoreceptor lipid composition affects the outcome of light damage. OS contain very high levels of polyunsaturated fatty acids, especially DHA, present at 30 to $50 \mathrm{~mol} \%$. This environment, together with high oxygen levels and light energy, is thought to create a particular vulnerability to oxidative stress. ${ }^{60}$ However, evidence for the role of DHA in cell degeneration is conflicting because both beneficial and detrimental effects have been observed. DHA-depleted rats were found to exhibit reduced retinal ILE damage in several studies. ${ }^{61-64}$ On the contrary, rats fed DHA-enriched diets acquired increased amounts of DHA in OS membranes but no apparent increase in peroxidation in vivo. ${ }^{65} \mathrm{DHA}$ also has neuroprotective effects on isolated photoreceptors in culture, ${ }^{66}$ and esterified DHA is converted to a protective docosanoid, neuroprotectin D-1, by a combination of phospholipase A2 and lipoxygenase-like enzyme activity within the retinal 

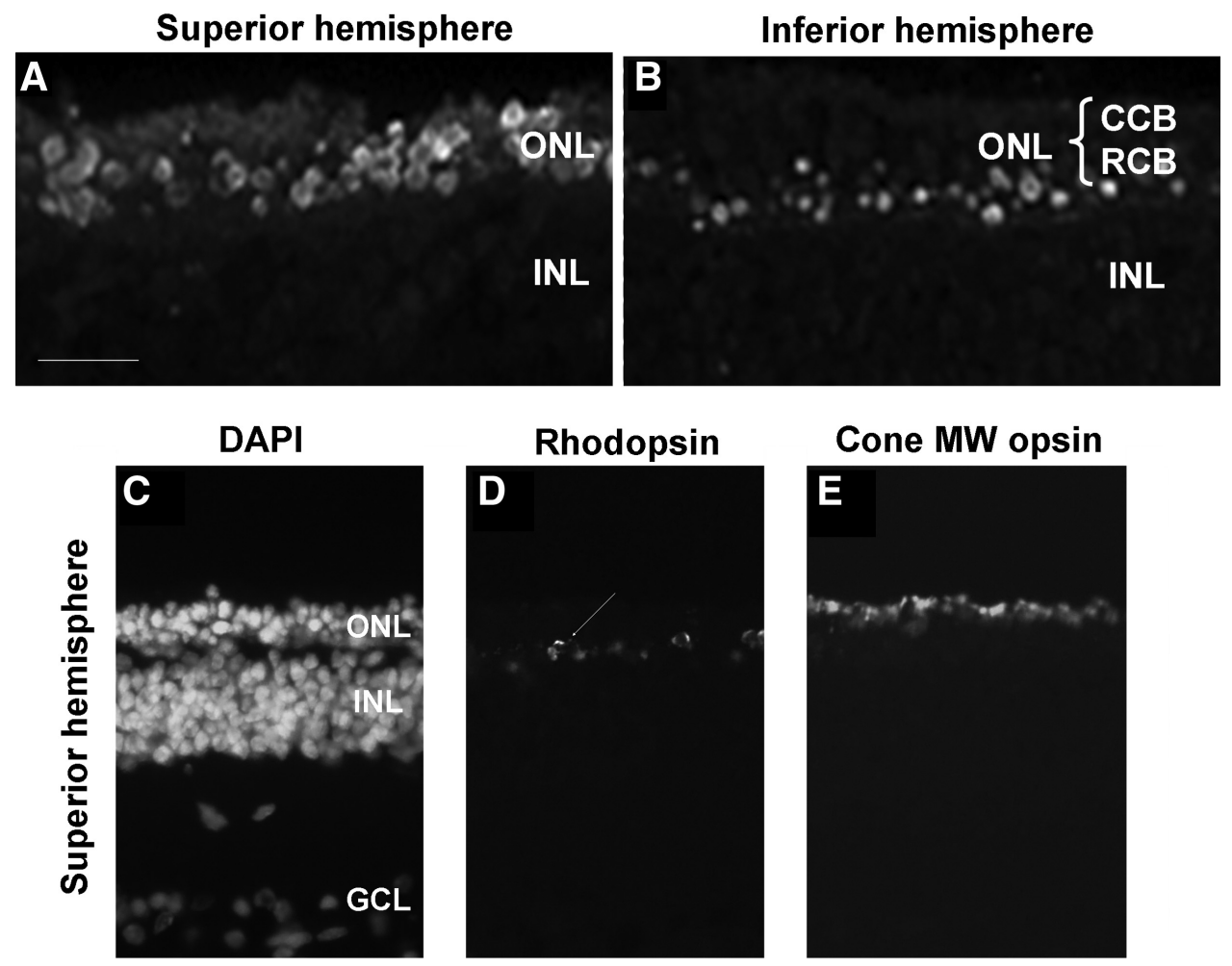

Figure 10. High doses of MNU induce apoptosis and preferential rod loss in $A$. ansorgei photoreceptors in a temporal, spatial, and subpopulation-dependent manner. (A, B) TUNEL staining. (C-H) Immunohistochemistry using rod and cone antibody markers. (A) Sections obtained from the midperipheral superior retina and treated for TUNEL reaction show widespread positive reaction product throughout the remaining disorganized ONL. (B) Corresponding sections from the inferior retina show a partitioned distribution of apoptotic nuclei, with TUNEL figures visible at the level of the rod cell bodies (RCB) in the lower ONL, whereas cone cell bodies in the upper ONL are unstained. There are no labeled nuclei in other layers. (C, F) DAPI-stained sections from superior and inferior retina, respectively. (D, G) Same fields showing rhodopsin (rod) staining. (E, H) Same fields showing MW cone opsin (cones) staining. Although both rod and cone staining is decreased in the superior field, rod staining is almost completely extinguished (scant remaining cell bodies, arrow), whereas cone staining is still robust. Scale bars: $40 \mu \mathrm{m}$ (A-C); $60 \mu \mathrm{m}$ (I).
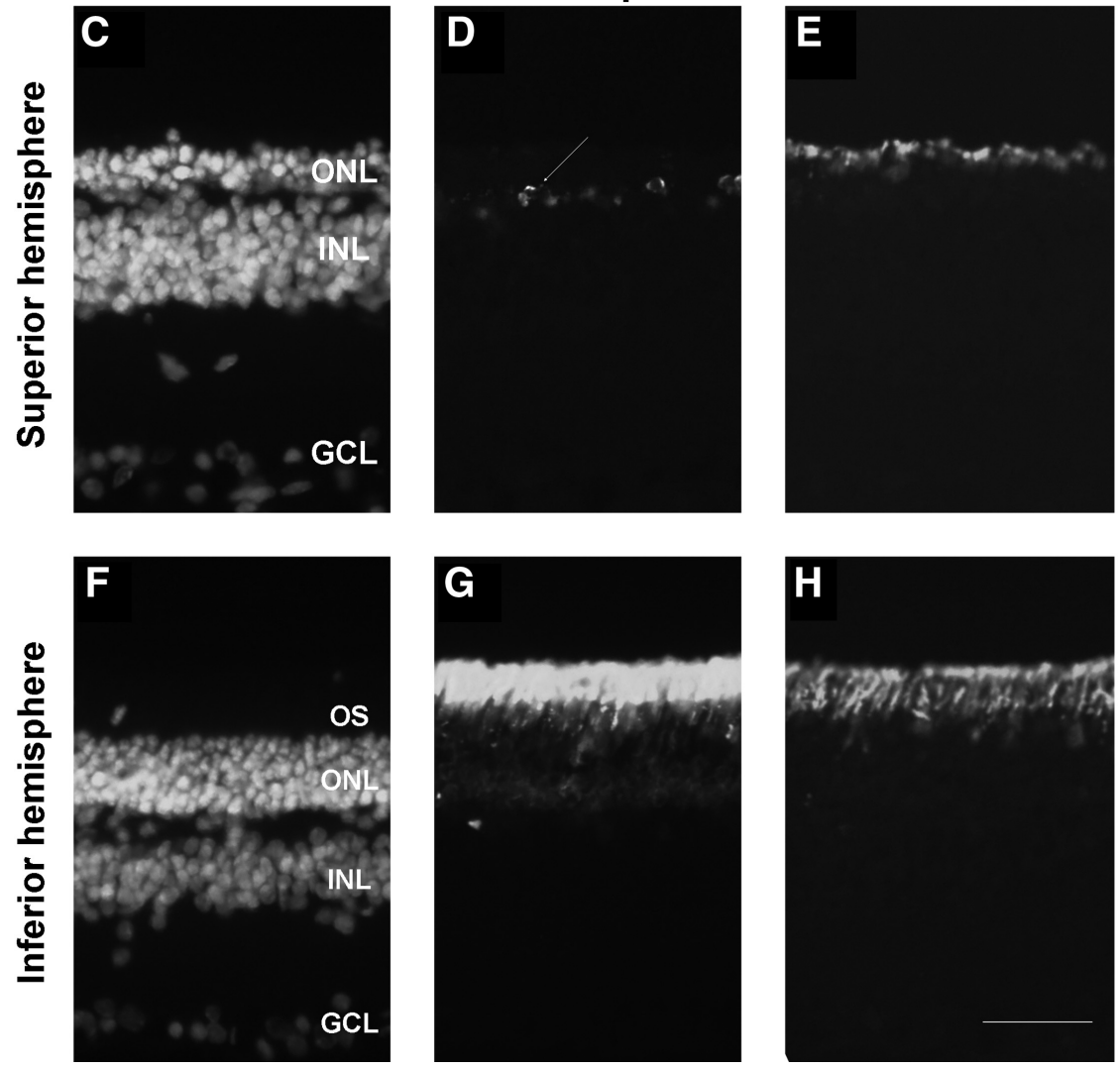

pigment epithelium. ${ }^{67}$ NPD-1 reduces oxidative stress-induced apoptosis in retinal pigment epithelium and brain tissue by upregulating the bcl-2 family of survival proteins while downregulating bax and other proapoptotic proteins. ${ }^{68}$ Although there were no major differences in lipid profiles between $A$. ansorgei and pigmented Brown Norway rat retinas, DHA was

TABle 2. Comparison of the Lipid Composition between A. ansorgei and Rat Retinas

\begin{tabular}{lcr}
\hline \multicolumn{1}{c}{ Lipid (FA) } & $\begin{array}{c}\text { A. ansorgei } \\
\text { (mean } \pm \text { SD) }\end{array}$ & \multicolumn{1}{c}{$\begin{array}{c}\text { Rat } \\
\text { (mean } \pm \text { SD) }\end{array}$} \\
\hline Saturated & $42.4 \pm 0.65 \dagger$ & $39.33 \pm 1.11$ \\
Monounsaturated & $11.75 \pm 0.18 \ddagger$ & $14.38 \pm 0.50$ \\
DMA & $6.07 \pm 0.16 \dagger$ & $6.50 \pm 1.67$ \\
Polyunsaturated & $39.74 \pm 0.65$ & $39.58 \pm 0.92$ \\
DHA & $26.11 \pm 0.48 \ddagger$ & $22.6 \pm 1.11$ \\
\hline
\end{tabular}

Results are expressed as percentages of total FA. DHA, docosahexaenoic acid; DMA, dimethyl acetal; FA, fatty acid.

$$
\dagger P \leq 0.01 ; \neq P \leq 0.001 \text {. }
$$

significantly enriched in the diurnal rodent retina, suggesting that if it is involved in resistance it acts as a beneficial factor. These lipid analyses were performed with whole retina, and we aim to perform similar experiments on OS preparations that will provide more accurate comparisons.

Wenzel et al. ${ }^{51}$ have shown that polymorphisms in the visual cycle of retinal isomerase RPE65 generate mouse strains that have shown slower rhodopsin regeneration kinetics and greater resistance to light damage. Our group sequenced $A$. ansorgei RPE65 (Felder MP, unpublished data, 2010) and found only the normal Leu- 450 form; therefore, the increased resistance was not due to visual cycle differences.

Another important facet of this study involves the effects of induced degeneration on cones. Cicerone ${ }^{27}$ and LaVail ${ }^{69}$ each noted cone survival in the ILE albino rat retina, suggesting that cones are more resilient than rods. On the contrary, cone degeneration was rapid in another model, ${ }^{26}$ and several studies have recorded cone death, which typically occurs after rod degeneration..$^{70,71}$ It is widely believed that cone demise in a variety of diseases is secondary to loss of surrounding rods, which could deprive cones of a rod-derived survival factor ${ }^{72}$ or 
possibly induce oxidative stress toxic to cones. ${ }^{58,73}$ When cone degeneration did occur in our study (in the superior hemisphere of animals receiving high doses of MNU), it was approximately overlapping with that of rods (within the time frame of our samples), but there was a clear separation of rod and cone cell breakdown in the inferior retina. This may indicate either a regional difference in cones or an insult sufficiently aggressive as to kill both types. Cortina et al. ${ }^{26}$ also noted simultaneous ILE rod and cone degeneration in the superior region of the rat retina. We contend that nocturnal rodent retinas are ill adapted to human cone pathophysiology because of their low cone numbers and sparse generalized distribution across the retina. Although humans, too, are rod dominant ( $\sim 95 \%$ rods), cones are concentrated into a specialized central macula subserving high-acuity stereoscopic vision. Cone death within the macula is responsible for major visual handicap in a number of human retinal diseases, including age-related macular degeneration and Stargardt's disease. The animal model used herein is of special interest in that it has a large cone population amenable to structural and functional analysis that contributes to both scotopic and photopic visually evoked responses. Flicker ERGs demonstrated robust cone responses in $A$. ansorgei at $30 \mathrm{~Hz}$, similar to ERG recordings from humans, whereas mouse cones were unable to respond at frequencies above approximately $10 \mathrm{~Hz}$.

It seems intuitive that retinas in diurnal species should be more resistant to the damaging effects of light radiation than species active in dim light. Comparisons of vulnerability between animals from both groups bear out this idea because, at similar light exposures, nocturnal rodents and primates exhibited greater photoreceptor damage than diurnal rodents in this study and others. ${ }^{48,74-76}$ Part of the difference resides in some daylight-active species having ultraviolet filtering yellow lenses (e.g., gray squirrels ${ }^{76}$ ). A. ansorgei does not have such a yellow-tinted lens, despite the high ambient light conditions to which it is exposed in its natural environment (semiarid desert regions across north and west Africa). Solovei et al. ${ }^{77}$ have reported fundamental differences in rod nuclear chromatin structure between nocturnal and diurnal mammals. They suggest that rod nuclei in nocturnal species have evolved to increase photon capture compared with those of diurnal species. By having a lower quantum catch, diurnal rods would be less vulnerable to damage, whereas the efficient capture of photons in nocturnal rods would enhance the likelihood of rod and cone damage. Indeed $A$. ansorge $i$ rod nuclei correspond to the diurnal type (Joffe $B$, personal communication, 2010). Whatever the reason, we were unable to induce photoreceptor-specific damage in $A$. ansorge $i$ by use of ILE paradigms. The only case in which degeneration was observed was through exposure to intense blue light, at some 50-fold higher intensity than that necessary for photoreceptor damage in mice. Degeneration was focal and involved the entire retinal thickness, resembling laser burn more than "classic" phototoxicity.

In conclusion, the effects of intense or prolonged light exposure on the retina vary greatly among species and according to variations in sector, daily time, light rearing history, and genetic background. The data indicate that damage or cell death mechanisms are not easily extrapolated between species or toward human blindness. Diurnal rodents could provide useful models for identifying naturally evolved protective or repair mechanisms that appear to confer great resilience in retinas. They may also provide a means for exploring various environmental and hereditary sensitizers to light damage, particularly those that may endanger cones.

\section{Acknowledgments}

The authors thank Corina Bobu for help with initial histologic work, Charlotte Remé and Christian Grimm for helpful discussions and valuable advice regarding light damage procedures, Dominique Sage for expert assistance, and Daniel Bonn for animal care and attentive oversight of the A. ansorgei colony.

\section{References}

1. Resnikoff S, Pascolini D, Etya'ale D, et al. Global data on visual impairment in the year 2002. Bull World Health Organ. 2004;82: $844-851$.

2. Borras T. Recent developments in ocular gene therapy. Exp Eye Res. 2003;76:643-652.

3. Novack GD. Emerging drugs for ophthalmic diseases. Expert Opin Emerg Drugs. 2003;8:251-266.

4. Ray K, Mukhopadhyay A, Acharya M. Recent advances in molecular genetics of glaucoma. Mol Cell Biochem. 2003;253:223-231.

5. Lyssenko V, Nagorny CL, Erdos MR, et al. Common variant in MTNR1B associated with increased risk of type 2 diabetes and impaired early insulin secretion. Nat Genet. 2009;41:82-88.

6. Hageman GS, Anderson DH, Johnson LV, et al. A common haplotype in the complement regulatory gene factor $\mathrm{H}(\mathrm{HF} 1 / \mathrm{CFH})$ predisposes individuals to age-related macular degeneration. Proc Natl Acad Sci U S A. 2005;102:7227-7232.

7. Clemons TE, Milton RC, Klein R, Seddon JM, Ferris FL 3rd. Risk factors for the incidence of Advanced Age-Related Macular Degeneration in the Age-Related Eye Disease Study (AREDS) AREDS report no. 19. Ophthalmology. 2005;112:533-539.

8. Taylor HR, West S, Munoz B, Rosenthal FS, Bressler SB, Bressler NM. The long-term effects of visible light on the eye. Arch Ophthalmol. 1992;110:99-104.

9. Pieramici DJ, Bressler SB. Age-related macular degeneration and risk factors for the development of choroidal neovascularization in the fellow eye. Curr Opin Ophthalmol. 1998;9:38-46.

10. Paskowitz DM, LaVail MM, Duncan JL. Light and inherited retinal degeneration. Br J Ophthalmol. 2006;90:1060-1066.

11. Wenzel A, Grimm C, Samardzija M, Reme CE. Molecular mechanisms of light-induced photoreceptor apoptosis and neuroprotection for retinal degeneration. Prog Retin Eye Res. 2005;24:275306.

12. Wu J, Seregard S, Algvere PV. Photochemical damage of the retina. Surv Ophthalmol. 2006;51:461- 481.

13. Organisciak DT, Vaughan DK. Retinal light damage: mechanisms and protection. Prog Retin Eye Res. 2009;29:113-134.

14. Williams TP, Howell WL. Action spectrum of retinal light-damage in albino rats. Invest Ophthalmol Vis Sci. 1983;24:285-287.

15. Rapp LM, Tolman BL, Koutz CA, Thum LA. Predisposing factors to light-induced photoreceptor cell damage: retinal changes in maturing rats. Exp Eye Res. 1990;51:177-184.

16. Keller C, Grimm C, Wenzel A, Hafezi F, Reme C. Protective effect of halothane anesthesia on retinal light damage: inhibition of metabolic rhodopsin regeneration. Invest Ophthalmol Vis Sci. 2001;42:476- 480 .

17. Sieving PA, Chaudhry P, Kondo M, et al. Inhibition of the visual cycle in vivo by 13-cis retinoic acid protects from light damage and provides a mechanism for night blindness in isotretinoin therapy. Proc Natl Acad Sci U S A. 2001;98:1835-1840.

18. Chen J, Simon MI, Matthes MT, Yasumura D, LaVail MM. Increased susceptibility to light damage in an arrestin knockout mouse model of Oguchi disease (stationary night blindness). Invest Ophthalmol Vis Sci. 1999; 40:2978-2982.

19. Hao W, Wenzel A, Obin MS, et al. Evidence for two apoptotic pathways in light-induced retinal degeneration. Nat Genet. 2002; 32:254-260.

20. Ogino $\mathrm{H}$, Ito $\mathrm{M}$, Matsumoto $\mathrm{K}$, et al. Retinal degeneration induced by N-methyl-N-nitrosourea and detection of 7-methyldeoxyguanosine in the rat retina. Toxicol Pathol. 1993;21:21-25.

21. Yuge K, Nambu H, Senzaki H, et al. N-methyl-N-nitrosourea-induced photoreceptor apoptosis in the mouse retina. In Vivo. 1996; 10:483- 488. 
22. Taomoto M, Nambu $H$, Senzaki $H$, et al. Retinal degeneration induced by $\mathrm{N}$-methyl-N-nitrosourea in Syrian golden hamsters. Graefes Arch Clin Exp Opbthalmol. 1998;236:688-695.

23. Petrin D, Baker A, Coupland SG, et al. Structural and functional protection of photoreceptors from MNU-induced retinal degeneration by the X-linked inhibitor of apoptosis. Invest Ophthalmol Vis Sci. 2003;44:2757-2763.

24. Yoshizawa K, Yang J, Senzaki H, et al. Caspase-3 inhibitor rescues $\mathrm{N}$ - methyl-N-nitrosourea-induced retinal degeneration in SpragueDawley rats. Exp Eye Res. 2000;71:629-635.

25. Moriguchi K, Yoshizawa K, Shikata N, et al. Suppression of Nmethyl-N-nitrosourea-induced photoreceptor apoptosis in rats by docosahexaenoic acid. Opbthalmic Res. 2004;36:98-105.

26. Cortina MS, Gordon WC, Lukiw WJ, Bazan NG. Light-induced photoreceptor damage triggers DNA repair: differential fate of rods and cones. Adv Exp Med Biol. 2003;533:229-240.

27. Cicerone CM. Cones survive rods in the light-damaged eye of the albino rat. Science. 1976;194:1183-1185.

28. Bobu C, Craft CM, Masson-Pevet M, Hicks D. Photoreceptor organization and rhythmic phagocytosis in the Nile rat Arvicantbis ansorgei: a novel diurnal rodent model for the study of cone pathophysiology. Invest Ophthalmol Vis Sci. 2006;47:3109-3118.

29. Szel A, Rohlich P. Two cone types of rat retina detected by anti-visual pigment antibodies. Exp Eye Res. 1992;55:47-52.

30. Jeon CJ, Strettoi E, Masland RH. The major cell populations of the mouse retina. J Neurosci. 1998;18:8936-8946.

31. Bobu C, Lahmam M, Vuillez P, Ouarour A, Hicks D. Photoreceptor organisation and phenotypic characterization in retinas of two diurnal rodent species: potential use as experimental animal models for human vision research. Vision Res. 2008;48:424-432.

32. Cuesta M, Clesse D, Pevet P, Challet E. From daily behavior to hormonal and neurotransmitters rhythms: comparison between diurnal and nocturnal rat species. Horm Behav. 2009;55:338-347.

33. Kaldi I, Martin RE, Huang H, Brush RS, Morrison KA, Anderson RE Bright cyclic rearing protects albino mouse retina against acute light-induced apoptosis. Mol Vis. 2003;9:337-344.

34. Organisciak DT, Xie A, Wang HM, Jiang YL, Darrow RM, Donoso LA. Adaptive changes in visual cell transduction protein levels: effect of light. Exp Eye Res. 1991;53:773-779.

35. Organisciak DT, Darrow RM, Barsalou L, et al. Light history and age-related changes in retinal light damage. Invest Opbthalmol Vis Sci. 1998;39:1107-1116.

36. Organisciak DT, Darrow RM, Barsalou L, Kutty RK, Wiggert B Circadian-dependent retinal light damage in rats. Invest Ophthal mol Vis Sci. 2000;41:3694-3701.

37. Vaughan DK, Nemke JL, Fliesler SJ, Darrow RM, Organisciak DT Evidence for a circadian rhythm of susceptibility to retinal light damage. Photochem Photobiol. 2002;75:547-553.

38. Li F, Cao W, Anderson RE. Protection of photoreceptor cells in adult rats from light-induced degeneration by adaptation to bright cyclic light. Exp Eye Res. 2001;73:569-577.

39. Grimm C, Wenzel A, Hafezi F, Yu S, Redmond TM, Reme CE Protection of Rpe65-deficient mice identifies rhodopsin as a mediator of light-induced retinal degeneration. Nat Genet. 2000;25: 63-66.

40. Miki K, Uehara N, Shikata N, Matsumura M, Tsubura A. Poly (ADP-ribose) polymerase inhibitor 3-aminobenzamide rescues $\mathrm{N}$ methyl-N-nitrosourea-induced photoreceptor cell apoptosis in Sprague-Dawley rats through preservation of nuclear factor-kappaB activity. Exp Eye Res. 2007;84:285-292.

41. Seeliger MW, Grimm C, Ståhlberg F, et al. New views on RPE65 deficiency: the rod system is the source of vision in a mouse mode of Leber congenital amaurosis. Nat Genet. 2001;29:70-74.

42. Schnebelen C, Pasquis B, Salinas-Navarro M, et al. A dietary combination of omega- 3 and omega- 6 polyunsaturated fatty acids is more efficient than single supplementations in the prevention of retinal damage induced by elevation of intraocular pressure in rats. Graefes Arch Clin Exp Opbthalmol. 2009;247:1191-1203

43. Tanimoto N, Muehlfriedel RL, Fischer MD, et al. Vision tests in the mouse: Functional phenotyping with electroretinography. Front Biosci. 2009;14:2730-2737.

44. Bretillon L, Acar N, Seeliger MW, et al. ApoB100,LDLR-/- mice exhibit reduced electroretinographic response and cholesteryl es- ters deposits in the retina. Invest Opbthalmol Vis Sci. 2008;49: 1307-1314.

45. Folch J, Lees M, Sloane Stanley GH. A simple method for the isolation and purification of total lipides from animal tissues. $\mathrm{J} \mathrm{Biol}$ Chem. 1957;226:497-509

46. Morrison WR, Smith LM. Preparation of fatty acid methyl esters and dimethylacetals from lipids with boron fluoride-methanol. $J$ Lipid Res. 1964;5:600-608.

47. Bobu C, Hicks D. Regulation of retinal photoreceptor phagocytosis in a diurnal mammal by circadian clocks and ambient lighting. Invest Ophthalmol Vis Sci. 2009;50:3495-3502.

48. Noell WK, Walker VS, Kang BS, Berman S. Retinal damage by light in rats. Invest Opbthalmol. 1966;5:450-473.

49. Kaitz M, Auerbach E. Action spectrum for light-induced retinal degeneration in dystrophic rats. Vision Res. 1979;19:1041-1044.

50. Humphries MM, Rancourt D, Farrar GJ, et al. Retinopathy induced in mice by targeted disruption of the rhodopsin gene. Nat Genet. 1997; 15:216-219.

51. Wenzel A, Reme CE, Williams TP, Hafezi F, Grimm C. The Rpe65 Leu450Met variation increases retinal resistance against light-induced degeneration by slowing rhodopsin regeneration. J Neurosci. 2001;21:53-58.

52. Nagar S, Krishnamoorthy V, Cherukuri P, Jain V, Dhingra NK. Early remodeling in an inducible animal model of retinal degeneration. Neuroscience. 2009;160:517-529.

53. Yoshizawa K, Nambu H, Yang J, et al. Mechanisms of photoreceptor cell apoptosis induced by $\mathrm{N}$-methyl-N-nitrosourea in SpragueDawley rats. Lab Invest. 1999;79:1359-1367.

54. Rapp LM, Williams TP. A parametric study of retinal light in albino and pigmented rats. In: Williams TP, Baker BN, eds. The Effects of Constant Light on Visual Processes. New York: Plenum Press; 1980:133-159.

55. Rapp LM, Jose JG, Pitts DG. DNA repair synthesis in the rat retina following in vivo exposure to $300-\mathrm{nm}$ radiation. Invest Ophthalmol Vis Sci. 1985;26:384-388.

56. Penn JS, Anderson RE. Effect of light history on rod outer-segment membrane composition in the rat. Exp Eye Res. 1987;44:767-778.

57. Liu C, Peng M, Laties AM, Wen R. Preconditioning with bright light evokes a protective response against light damage in the rat retina. J Neurosci. 1998;18:1337-1344.

58. Stone J, Maslim J, Valter-Kocsi K, et al. Mechanisms of photoreceptor death and survival in mammalian retina. Prog Retin Eye Res. 1999;18:689-735.

59. Li F, CaO W, Anderson RE. Alleviation of constant-light-induced photoreceptor degeneration by adaptation of adult albino rat to bright cyclic light. Invest Ophthalmol Vis Sci. 2003;44:4968-4975.

60. Winkler BS. An hypothesis to account for the renewal of outer segments in rod and cone photoreceptor cells: renewal as a surrogate antioxidant. Invest Ophthalmol Vis Sci. 2008;49:32593261.

61. Organisciak DT, Wang HM, Noell WK. Aspects of the ascorbate protective mechanism in retinal light damage of rats with normal and reduced ROS docosahexaenoic acid. Prog Clin Biol Res. 1987; 247:455-468

62. Organisciak DT, Darrow RM, Jiang YL, Blanks JC. Retinal light damage in rats with altered levels of rod outer segment docosahexaenoate. Invest Opbthalmol Vis Sci. 1996;37:2243-2257.

63. Bush RA, Reme CE, Malnoe A. Light damage in the rat retina: the effect of dietary deprivation of N-3 fatty acids on acute structural alterations. Exp Eye Res. 1991;53:741-752.

64. Wiegand RD, Koutz CA, Chen H, Anderson RE. Effect of dietary fat and environmental lighting on the phospholipid molecular species of rat photoreceptor membranes. Exp Eye Res. 1995;60:291-306.

65. Wang JY, Saito M. Dietary supplementation of N-3 fatty acids and hydroperoxide levels in rat retinas. Free Radic Res. 2001;35:367375.

66. Rotstein NP, Politi LE, German OL, Girotti R. Protective effect of docosahexaenoic acid on oxidative stress-induced apoptosis of retina photoreceptors. Invest Ophthalmol Vis Sci. 2003;44:22522259.

67. Mukherjee PK, Marcheselli VL, Serhan CN, Bazan NG. Neuroprotectin D1: a docosahexaenoic acid-derived docosatriene protects 
human retinal pigment epithelial cells from oxidative stress. Proc Natl Acad Sci US A. 2004;101:8491-8496.

68. Bazan NG. Neuroprotectin D1 (NPD1): a DHA-derived mediator that protects brain and retina against cell injury-induced oxidative stress. Brain Patbol. 2005;15:159-166.

69. La Vail MM. Survival of some photoreceptor cells in albino rats following long-term exposure to continuous light. Invest Ophthal mol. $1976 ; 15: 64-70$

70. Tanito M, Kaidzu S, Anderson RE. Delayed loss of cone and re maining rod photoreceptor cells due to impairment of choroida circulation after acute light exposure in rats. Invest Opbthalmol Vis Sci. 2007;48:1864-1872.

71. Krebs MP, White DA, Kaushal S. Biphasic photoreceptor degeneration induced by light in a T17M rhodopsin mouse model of cone bystander damage. Invest Ophthalmol Vis Sci. 2009;50:29562965.
72. Leveillard T, Mohand-Said S, Lorentz O, et al. Identification and characterization of rod-derived cone viability factor. Nat Genet. 2004;36:755-759.

73. Komeima K, Rogers BS, Lu L, Campochiaro PA. Antioxidants reduce cone cell death in a model of retinitis pigmentosa. Proc Natl Acad Sci U S A. 2006;103:11300-11305.

74. Fuller D, Machemer R, Knighton RW. Retinal damage produced by intraocular fiber optic light. Am J Ophthalmol. 1978;85:519-537.

75. Tso MO. Retinal photic injury in normal and scorbutic monkeys. Trans Am Ophthalmol Soc. 1987;85:498-556.

76. Collier RJ, Waldron WR, Zigman S. Temporal sequence of changes to the gray squirrel retina after near-UV exposure. Invest Ophthalmol Vis Sci. 1989;30:631-637.

77. Solovei I, Kreysing M, Lanctot C, et al. Nuclear architecture of rod photoreceptor cells adapts to vision in mammalian evolution. Cell. $2009 ; 137: 356-368$. 